This is a self-archived version of an original article. This version may differ from the original in pagination and typographic details.

Author(s): Hedström, Axel; Zelander, Nathalie; Junttila, Juha-Pekka; Uddin, Gazi Salah

Title: Emerging Market Contagion Under Geopolitical Uncertainty

Year: 2020

Version: Accepted version (Final draft)

Copyright: (C) Taylor \& Francis Group, LLC

Rights: In Copyright

Rights url: http://rightsstatements.org/page//nC/1.0/?language=en

Please cite the original version:

Hedström, A., Zelander, N., Junttila, J.-P., \& Uddin, G. S. (2020). Emerging Market Contagion Under Geopolitical Uncertainty. Emerging Markets Finance and Trade, 56(6), 1377-1401. https://doi.org/10.1080/1540496X.2018.1562895 


\title{
Emerging Market Contagion Under Geopolitical Uncertainty
}

\author{
Axel Hedström \\ Department of Management and Engineering, \\ Linköping University, 581 83, Linköping, Sweden \\ E-mail: hedstrom.axel@gmail.com \\ Nathalie Zelander \\ Volkswagen Finans Sverige AB \\ nathalie.zelander@vwfs.se \\ Juha Junttila* \\ Department of Economics, \\ University of Jyväskylä, School of Business and Economics, \\ PO Box 35, FI-40014 University of Jyväskylä, Finland \\ E-mail: juha-pekka.j-p.junttila@jyu.fi \\ Gazi Salah Uddin \\ Department of Management and Engineering, \\ Linköping University, 581 83, Linköping, Sweden \\ E-mail: gazi.salah.uddin@liu.se
}

This version: 17 December 2018

*Corresponding author 


\begin{abstract}
We find that ten emerging stock markets have high risk of contagion on the regional level but lower spillover with respect to the global markets, implying a potential for diversification benefits between emerging and global markets. Regional market integration seems to have been caused by trade integration, which has a policy implication for trade agreements' systemic risk effects. We find that the geopolitical risk has no impact on either the return, or volatility spillovers. However, the general stock market risk (VIX) is connected to individual market volatilities, while the oil market is largely receiving the spillovers from the other markets.
\end{abstract}

Keywords: Spillover, Equity market, Contagion, Financial crises

\title{
1. Introduction
}

The top performing emerging markets, e.g., China and Korea, have shown strong economic and financial development in the last decades (Bloomberg, 2013a). Global investors seeking the most profitable investment opportunities are naturally drawn to these emerging markets, due to their economic performance. However, the risks associated with economic and financial development are connected to market integration. This could lead to transmission of shocks across markets, or spillover, that deteriorates the prominent investment opportunities by reducing diversification possibilities.

To measure these connections, the previous literature mainly measures the spillover effects between asset markets based on bivariate return correlation (see e.g. Balli et al., 2015, and Kundu and Sarkar, 2016). Among the few exceptions to this approach are Pukthuanthong and Roll (2009) and Demirer et al. (2017), who use principle component analysis (PCA) and vector autoregressive (VAR) type models, respectively, to measure the spillover effects. Studies that focus on correlations often miss out important aspects related to the uncertainty of economic activity and policies. Recently, some studies have noticed this deficiency in the literature. For example, Tsai (2017) controls for the Economic Policy Uncertainty (EPU) effects in analysing the stock market contagion for various countries.

As an alternative uncertainty measure, based on the impact on the financial market by events such as the Brexit referendum, the US-election and 9/11, that had large impacts on existing stock markets, we propose that the geopolitical uncertainty might affect the investor sentiment, and hence, the stock market movements. Furthermore, geopolitical uncertainty might have more dire effects in developed markets compared to the emerging markets. Diamonte et al. (1996) argue that the developed markets have become more politically turbulent, while the emerging markets have become more politically stable. We believe this holds some truth to it, with the changing political climate during the last two decades. Some 
definite observed events for an extreme increase in political uncertainty are the Iraq War, bombings in London and Barcelona, annexation of Crimea, and rising populism. From financial investors' perspective, there could be other downsides from investments to emerging markets, and to control for that we also use other uncertainty indicators in our analysis, i.e., the measures for the stock market risk (VIX), and the commodity market risk (crude oil price variation). While the geopolitical risk (GPR) measure mimics the risk involved in terrorism, war and conflicts, the VIX captures the financial (stock market) risk and the oil market measure mirrors the development in the real economy/commodity market risks. By capturing a broad spectrum of uncertainties, we will try to distinguish between the questions on

(i) what type of uncertainty has spillover effects on the emerging markets;

(ii) what type of risks should investors assess when deciding where to invest; and

(iii) are the spillovers homogeneous among the emerging market countries?

All our analyses are based on using monthly data from January 1995 to December 2016 from 10 emerging markets and a method based on a Vector AutoRegressive (VAR) model with generalized variance decomposition (GVD) following the Diebold and Yilmaz (2014) approach.

The main contribution of this paper is first of all, the inclusion of geopolitical risk (GPR) to show how it affects the findings. We find that the GPR shows weak to no spillover to all stock markets (less than 1.5\%). This indicates that geopolitical issues in general have weak impact on the stock markets, but it does not indicate that none of the geopolitical events have any effects. For robustness, the GPR results are compared to the results using the Global Economic Policy Uncertainty (GEPU) index (see Davis 2016), that is based on a weighted country level Economic Policy Uncertainty (EPU) index of Baker et al. (2016). GEPU shows stronger spillover to the stock markets, thus indicating that the stock markets are more sensitive to the economic and political aspects than to geopolitical issues. The second main finding of this paper is that the emerging mark spillovers are more essential at the regional level, and we argue that this relationship is strengthened by the trade agreements. In other words, the spillover effects amongst e.g. the Asian countries are higher and the reason for this might be the increased trade among these countries, related to the free trade agreements. This finding should guide policy legislation to a degree when negotiating the agreements to minimize the contagion effects in the future. Our third major finding is that oil prices receive the volatility spillovers from all the other markets, and this indicates the strong role of financialization of crude oil markets. 
The paper is structured as follows. In section 2 we present some stylized facts on our chosen countries, and discuss the previous literature connected to our study. Section 3 discusses the descriptive data and preliminary analysis, section 4 presents the method, and in section 5 , we present and analyse our results, and check for the stability of those. Finally, section 6 concludes our findings and provides some policy implications, too.

\section{Financial Development in Emerging Markets and Previous Studies}

The emerging markets are an eclectic group of countries loosely defined as economically 'on the rise'. To narrow our set of countries we single out the economically top performing countries and base our investigation on Bloomberg's definition of the most promising markets (Bloomberg 2013b). They form natural selection criteria based on economic activities and investment opportunities. ${ }^{1}$ The top ten countries were selected as the most promising emerging markets with the greatest stock market prospects. The chosen countries were: Chile, Peru, China, Indonesia, Malaysia, Thailand, Korea, Czech Republic, Russia, and Turkey.

The financial market data in Table 1 suggest that the chosen emerging markets' financial sector is developing. The market capitalization has increased for the countries since 1995, indicating an increased market potential, except for the Czech Republic. ${ }^{2}$ This has also been accompanied by an increased number of company listings suggesting increasing ability of companies to attract capital to these countries. They also show high liquidity with the exception of Chile, Peru and Czech Republic.

\section{$<$ Insert Table 1 about here $>>$}

The data on trade development are more spurious and depend on the specific country (see Table 2). Here Chile and Peru have had a stable trade percentage share of GDP, similar to

\footnotetext{
${ }^{1}$ The selection criteria used by Bloomberg are composed of a dozen variables. For economic outlook, they look at the IMF forecasts for GDP growth, inflation, government debt, and total investment. From the World Bank database, they took demographic and economic development. The literacy rate, age of population, labour market participation, and electricity consumption are taken from the International Energy Agency. For financial markets, they use the price earnings ratios of equities, liquidity and currency volatility from the Bloomberg financial dataset. They also include Ease of Doing Business Index from the World Bank, Corruption Perceptions Index from Transparency International and the Wall Street Journal/Heritage Foundation's Index of Economic Freedom. Altogether, these make up a good and stable set of selection criteria among the emerging countries.

${ }^{2}$ Russia has missing data from 1990-2010 in the World Development Index (WDI) database, but it has a high company listing and market capitalization for the existing time periods.
} 
the South East Asian countries. The South East Asian countries increased their trade percentage share of GDP before 2007 but have stabilized on a lower level after the crisis. Malaysia stands out with a high trade percentage share of GDP for all time periods. For the European countries, the Czech Republic shows increasingly higher trade which probably originates from the EU membership and a higher trade integration from combined trade policy. For the non-EU members, Russia's and Turkey's trade percentage share of GDP is relatively stable over time.

\section{$<<$ Insert Table 2 about here $>>$}

From Table 2 we see that in Peru and Chile foreign direct investment (FDI) inflows have been negative but the portfolio equity investments have been positive for both countries. This indicates net investment in other countries' production but net increases in their equity markets. On the other hand, portfolio investments in the South East Asian region do not follow a linear pattern, but seem to be increasing in overall terms. Some emerging markets in this region have shown extreme increases during this period. China, for instance, had 51.92 billion USD in equity inflow in 2014 compared to 6.91 billion USD in 2000, and Korea had equity inflows that surmounted to 23.6 billion USD in 2010. The European countries' equity inflows have been spurious, and especially the Czech Republic has low FDI and equity inflows. Turkey and Russia show increasing FDI and equity inflows in the period 1996-2006 but decreasing values between 2006 and 2016. The latter observation might be caused by the increased political uncertainty in these countries especially during 2014-2016.

\section{$<<$ Insert Table 3 about here $>>$}

More details on the trade integration are given in Table 3. Japan has high positive net export with most of the South East Asian emerging markets except with Indonesia and Malaysia. The net exports between Japan and Indonesia were negative and stable throughout the analysed time period. However, Japan's trade flows with Malaysia have fluctuated, in 1995 the net exports were positive, then from 2000 onwards the trade relationship changed which indicates a transformation of the value of trade between the countries. For the South American countries, Peru and Chile, the net exports are heterogeneous throughout time but mostly negative. Japan has positive net exports with both the Czech Republic and Turkey. For JapanRussia pair it is the opposite, and the net exports show negative values for all of the period except in 2005 when the net exports were positive. This indicates that Japan has a positive net 
export situation in international trade with the industrialised emerging countries that have experienced rapid technological development, mainly in the South East Asian region, and negative net exports with emerging economies that have more commodity-based exports such as Russia and Indonesia.

The U.S. has high negative net exports with South East Asian countries, especially with China. Especially for South Korea the net exports fluctuate over time a lot. The net exports were positive in 1995 but changed to negative after 2000. The net exports flow between U.S. and Turkey was positive with a small decline during the period 2000-2005. The net exports between USA and the European countries, Russia and Czech Republic, were similar over this period. Both countries display negative net exports throughout the whole time period. For the relation between the U.S. and Czech Republic, the low negative net exports between 1995 and 2000 could be due to the economic growth that started to increase for the Czech Republic after 2000 with political and financial reforms after the crisis in 1997. The net export flows between the U.S. and the South American countries have fluctuated over time. On the other hand, the net exports between the U.S. and Peru have varied from the low in 2000 compared to other periods, which could be related to the political turbulence in Peru during that time that hindered also international trade. The net exports relationships between the U.S. and Chile show similar patterns to the net exports between the U.S. and Peru, with low U.S. net export values around 2000.

EU had a negative net exports balance with most of the emerging markets over the analysed sample period, but with some exceptions. The net export flows between the EU and South American countries have been lower, compared to the emerging markets from other continents, indicating a lower trade bond. For most of the South East Asian countries, China, Indonesia and Korea, the net exports with EU were positive in 1995 but shifted to negative values afterwards. For the East European countries of Russia and the Czech Republic, the net exports from EU were negative with the exception for Czech Republic between 1995 and 2005 when the net exports were positive. Trade flows between the EU and Turkey were positive for the whole of our analysed sample indicating a stable trade demand between them, although the situation may have changed after 2015, with increasing tension between Turkey and EU.

As observed from Tables 1 and 2, the financial markets have clearly developed in the emerging market economies, which gives clear reasons to invest in them. Furthermore, due to the strong rise in electronic forms of market trading, the investors could easily nowadays take more advantage of the diversification between the developed and emerging markets. As proposed by Levy and Sarnat (1970), due to possibilities of relatively high degree of positive 
correlation between the various asset returns in a closed economy, an overall risk reduction could be achieved by diversifying the securities portfolio internationally, and they argued that it is optimal to have an internationally diversified portfolio with assets both from developed and emerging markets.

Optimal diversification requires that the risks of different assets are independent of each other. However, this is not the case when the asset markets are affected by contagion. Contagion is the systemic risk for co-movements among assets (Forbes and Rigobon, 2001) which obviously worsens the benefits of diversification. Thus, a seemingly well diversified portfolio may be full of systemic risks. Contagion may pose a greater risk for emerging markets as they suffer more from recessions with higher fall in consumption, while they also have a harder time recuperating (Carriere-Swallow and Crepedes, 2013). Interconnected with the definition of contagion are the concepts of spillover and market integration, which we will use as indicators of contagion.

The literature on market integration and contagion is large but we will focus on a few items most connected to our study. For example, Baig and Goldfajn (1999) showed that contagion was the reason for the South East Asian crisis. Diebold and Yilmaz (2009) created a spillover index based on VAR model and found strong spillover effects between the global markets especially during periods of high volatility. Furthermore, market integration acts like a prerequisite for contagion, since segmentation would lead to independent market movements. Pukthuanthong and Roll (2009) studied how the magnitude of market integration affects the spillover/contagion. Using principal component analysis they showed that there is low timevarying integration between the frontier markets and the global market. On the other hand, Diebold and Yilmaz (2013) argued that when a shock in one country is small, it cannot be expected to be transferred to other countries regardless of the integration among countries, contrary to what Pukthuanthong and Roll (2009) stated. Only if the shock is large enough, it can be transferred to other countries and the correlations between macroeconomic factors across countries increase. This means that small shocks in returns would not show spillover effects regardless of the amount of integration between countries. Berger et al. (2011) found some evidence that the frontier markets have been integrated with the global market. Based on structural break models they concluded that some frontier markets have had periods with decreasing and increasing integration. This would mean that integration between countries varies over time and this could mean that a crisis in one country affects the integration among a group of countries. In earlier studies, e.g. Caramazza et al. (2004) studied the financial 
linkages of the emerging markets during the crisis in the 1990s and found that financial linkages contributed strongly to this episode.

In the most recent studies, Babus (2016) used an endogenized bank network model to see how the financial system reacted to small shocks ${ }^{3}$. This means that the linkage between the banks is not fixed. She discovered that banks respond to contagion by forming links which are likely to support systemic stability. Furthermore, Demirer et al. (2017) investigated the bankto-bank spillover on the global level and found that the spillover is prevalent in the regional market. They also showed how the spillover was not proportional to the asset allocation.

Shin and Wang (2004) found that increasing trade among countries could cause the business cycle to move in two directions, i.e., either towards same or different directions. If the countries produce the goods that they have comparative advantages in, in line with the Heckscher-Ohlin model it would lead the industrial structures of the trading countries to go to different directions. If instead, increased trade occurs mainly through intra-industry trade, the business cycles of the countries trading with each other would become more synchronized. According to Shin and Wang (2004) a reason why increased trade would lead to a positive correlation with business cycle co-movements, is that if a demand shock drives a boom in one country, the effect can spill over to its trading countries. This is consistent with the findings of Greenwood-Nimmo et al. (2015) that equity plunges are affecting trade and GDP negatively. Duval et al. (2014) investigated the business cycles synchronization across the world, and their findings showed that it spikes across the globe during crises. The business cycle synchronization is much lower during the non-crisis periods but it has been increasing during the last two decades. This could be because of globalization.

Nowadays, the region with the highest synchronization is formed by the Asian countries: Indonesia, Malaysia, the Philippines, Singapore and Thailand. We use oil price as a control factor for the real economy risks since it is an indicator of inflation pressures, and inflation affects the returns on all types of investments. Sadorsky (1999) confirms that oil prices and oil price volatility do affect economic activity but not the other way around. GreenwoodNimmo et al. (2015) also found that the crude oil market is an important factor for the transmission of shocks in the global economy. In earlier studies, using a nonparametric copula approach for the period after the financial crisis, Bekiros and Uddin (2017) found a particularly strong interrelationship in the negative returns between the crude oil market and the EPU for the U.S. stock market. Reboredo and Uddin (2016) showed that there is no co-movement, and

\footnotetext{
${ }^{3}$ For an early study with exogeneous bank network see Allen and Gale (2000).
} 
no Granger causality between commodity prices and financial uncertainty or between commodity prices and policy uncertainty. They used a quantile regression for the period 1994 - 2015, that indicated strong connectedness of commodity markets to the stock markets and the need to implement this connection as an uncertainty measure. Bekiros et al. (2017) used time varying networks, with correlations and entropy to study the relationship between commodities and U.S. equities. They found among various relationships the strongest connection between oil futures transfer information (entropy) to equity market and that the energy equity sector is connected to oil market. This relationship has increased over time and points to financialization of the commodity market. Awartani and Maghyereh (2013) studied the spillover of return and volatility between equities and oil in the Gulf countries. They found that oil has had a net spillover to stocks with a greatest impact during the 2008 crisis.

Engle et al. (2012) used a multivariate extension of the multiplicative error model to study the volatility spillover on eight Asian markets. They modelled the interrelations of equity market volatility in these countries before, during and after the Asian crisis, and concluded that the dynamic propagation of volatility shocks occurs through a network of bilateral dependencies. More recently, Tsai (2017) studied the effects of economic policy uncertainty (EPU) in different regions by using the Diebold and Yilmaz (2014) VAR-model to see the risk of spillover on investments in the global stock market. The volatility risk was measured using a GARCH model. The effect of EPU was to determine the regional systematic risk on global stock markets and then the volatility risk on individual stock markets. Their results indicate that EPU in China is the most influential and the EPU in Japan hardly influences the spillover risk in emerging markets. However, according to the volatility risk, the EPU in China and Europe influence the Asian and European countries the most. An explanation for these results could be the high trade dependence among these countries. This is because the prospects of good performance of international firms are mainly determined by the economic policies of their trading partners.

\section{Descriptive Data and Preliminary Analysis}

We use monthly observations ranging from January 1995 to December 2016. All the stock indices are collected from the Morgan Stanley Capital International (MSCI) website. The crude oil prices are from Datastream, the VIX index from the Chicago Board Options Exchange (CBOE) and the GPR data from Caldara and Iacoviello (2017). 
The MSCI indices were used because they enable a coherent comparison of country stock prices and they are adjusted for other factors such as inflation. The indices are from the top ten emerging markets out of the top 20 promising ones according to Bloomberg (Bloomberg, 2013a). In this study, the aggregate stock indices are used to capture the overall spillover of one index to another but note that the effect of returns can vary due to sector weights. For example, Syriopoulos et al. (2015) concluded that the U.S. industrial sector had positive return spillover on the BRICS countries at the aggregate index level, but the financial sector only had spillover effects on Russia and South Africa.

The VIX index was collected from the CBOE as a forward-looking variable to measure the financial stress the economy is facing in the near future. Since its introduction by Brenner and Galai $(1989,1993)$, the use of VIX as a general financial market uncertainty indicator has been common for most asset classes. Oil is an important commodity for businesses and trade, and including it to our analysis controls for the real economic activity risk as in GreenwoodNimmo et al. (2015). As the measure for the global oil price level we chose the West Texas Intermediate (WTI) crude oil price index.

The geopolitical risk (GPR) index is a recently created index that measures the uncertainty associated with geopolitics. Using the GPR index enables testing specifically if the risks for terrorism, war etc. are important for contagion. According to our knowledge, no one has used this measure and approach to connect the geopolitical uncertainty with the spillover effects, and hence, it is necessary to establish the possible a priori link between these two. Figure 1 shows how the GPR index has evolved during the period of our analysis. Geopolitical uncertainty seems to have been the strongest during the period from 2001 to 2003 in connection with the terrorist attacks on 9/11 and the subsequent wars started by the U.S. in Afghanistan and Iraq. During the same period, there was a negative trend in the stock markets of the developed countries (Europe, Japan and the U.S.). This could indicate that the stock markets were affected by the GPR during this period. In addition, at the same time when the GPR decreased as the War in Iraq ended, there was a stabilization of the markets. The emerging markets seem not to have been affected by the geopolitical turmoil during this period, which is in line with the idea that the developed markets obtain higher uncertainty effects from the geopolitical uncertainty (Diamonte et al., 1996). The increase of the GPR in 2014 is due to the Crimean crises and the Russian acquisition of the Crimean Peninsula, but this has had little impact on the stock markets.

That the GPR is not correlated with the recession in 2008 is self-explanatory since that drop had much more to do with the collapse of the financial institutions. The VIX measure 
seems better at explaining this, as seen in panel c of Figure 3. The decrease in the VIX during the 2003 to 2007 period is connected to the increase of the stock market prices during this period, suggesting that stable market conditions and prospects incur growth in asset prices. Only China has a delayed increase in its stock index values, that is most likely linked to the relaxations of the Chinese financial market regulations.

\section{$<$ Insert Figure 1 about here $>>$}

In Table 4, the descriptive statistics from our sample are presented. The mean return per month is around $0.5 \%$ for the whole set of countries since the 1990 . When focusing on the mean return in contrast with the risk (standard deviation), Thailand seems the least attractive with negative mean return per month of $0.2 \%$ and high risk of $1.1 \%$. Stock market returns in general tend to be non-normal, which is shown by the Jarque-Bera test values in Table 4. However, Japanese stock returns seem to be normally distributed in our sample, although it is special finding in a sense that the economy of Japan has been in malaise since the late 1990's with stagnated growth. Japan and Europe show the least extreme tailedness which indicates more stable and less extreme market conditions. In the Supplementary Material online Appendix S.A, Table S.A2 we report the unit root test results, that imply that all the stock market indices are stationary upon differencing, i.e., the return series are stationary. In addition, the oil price series needs differencing before it can be used as a commodity market variable, while VIX and GPR should be used in levels for a modelling procedure requiring only stationary variables.

Figure 2 shows the unconditional correlations between the analysed variables, which will give us a priori indications on the spillover effects between different markets. European and the U.S. stock markets show high correlation with each other, suggesting that they are highly comoving and have high financial interaction. The Japanese market shows correlation with the European and the U.S. markets albeit not that high. Surprisingly, Japanese returns show higher correlation with the developed markets than with the regionally closer markets of China, Thailand, Malaysia etc. The Thai market seems to have higher correlation at least with Korean and Malaysian than the Japanese market. In the South East Asian markets, there seems to be high correlation between Thailand, Malaysia and Indonesia, suggesting some interaction between these markets. The VIX values show negative correlation with especially the European and U.S. markets. GPR shows mild negative correlation with all variables, except with VIX.

\section{$<$ Insert Figure 2 about here $>>$}


From panel a in Figure 3 we see that there is a clear dip for almost all returns during the 2008 recession and the stock market collapse. In traditional time series analyses this observation could be treated as an outlier. However, observing that many markets act in the same way during the same period of time could mean that there are large spillover effects. Another clear dip for several indices is linked to the Asian stock market crash from 1997 to 1998, and during that time, there was also the Russian crash of the Rubel, and subsequently, a stock market crash. In general, this indicates a period of turmoil in the emerging markets, where South East Asian countries, Russia and the South American countries experienced a bullish market. However, the IT-crash in the beginning of 2000 does not seem to have echoed as clearly as the previously mentioned ones, although in general, the period between 2000 and 2003 is a turbulent one based on the implied volatility in the markets.

\section{$<$ Insert Figure 3 about here $>>$}

\section{Econometric Methodology}

Our empirical analysis relies on the framework of Diebold and Yilmaz (2014) which is rooted to their earlier work (Diebold and Yilmaz, 2009). Put it simply, it utilizes the representation of the data in the form of a VAR model, from which the variance decomposition of the forecasting errors is extracted to produce a spillover index. In the original study, Diebold and Yilmaz (2009) base their variance decomposition on the recursive Cholesky orthogonalization of the residuals, which is sensitive to the ordering of the variables in the VAR model. This could lead to problems when they create their connectedness index. This was solved in their reworked model using the generalized variance decomposition (GVD) approach, which was introduced by Pesaran and Shin (1998), which builds on the previous work of Koop et al. (1996). This was implemented in Diebold and Yilmaz (2014). This method lets us to include more variables to the model whose effects would otherwise be hard to control, e.g., VIX, GPR and oil price, and use a multivariate framework. Otherwise, we could have looked at the bivariate correlations based on, e.g., AR-GARCH, Copula or Wavelet decompositions. Since we want to establish the link between several return variables and include to the analysis the effects of uncertainty measures, the Diebold and Yilmaz (2014) method is the most appropriate for our purposes.

As already mentioned, the spillover analysis starts from estimating a VAR model, popularized by Sims (1980), where the main assumption is that the data generating processes of the analysed variables are covariance-stationary. The Wold theorem states that a stochastic 
process can be split into two orthogonalized parts, i.e., a linear predictable and an unpredictable process. The predictable process relates to the lagged values and the unpredictable to the residuals. If the assumptions hold, this ensures covariance-stationarity, but linear transformations, like taking a lag or differencing of the ingoing variables can become necessary to achieve it (see Canova 2007). This involves also that shocks to the system $x_{t}=\Theta(L) u_{t}$ are orthogonal, i.e., that $x_{i, t} \mid u_{j, t}=0$, if $i \neq j$. Our estimated VAR model in structural form is

$$
R_{t}=\Theta R_{t-1}+\epsilon_{t} R_{t}
$$

where $R\left(r_{t}, U M_{t}\right)$ is the $1 \times 14$ return vector of the stock indices plus always only one uncertainty variable observed at time t. The returns are calculated as $r_{t}=\ln \left(\frac{P_{t}}{P_{t-1}}\right)$, where $P$ is the monthly closing price. $R_{t-1}$ is a $14 \times 14$ matrix containing lagged stock return indices and one of the uncertainty measurements (UM), and $\Theta$ is the coefficient matrix. The estimation is done with including one of the uncertainty measures of financial uncertainty (VIX), geopolitical uncertainty (GPR) or commodity risk (oil price change), at a time. From equation 1, the reduced form is calculated, since the structural form lacks the practical computational power. Hence, the reduced form VAR model for the analysis is given as

$$
\begin{array}{ccc}
\mathrm{E}_{1, t} & = & \mathrm{a}_{1} \mathrm{E}_{1, t-1}+\mathrm{a}_{2} \mathrm{E}_{2, t-1}+\cdots+\mathrm{a}_{n} \mathrm{E}_{n, t-1}+\mathrm{a}_{n+1} \mathrm{UM}_{t-1}+\epsilon_{1} \\
\vdots & & \vdots \\
\mathrm{E}_{n+1, t} & = & \mathrm{a}_{n} \mathrm{E}_{1, t-1}+\mathrm{a}_{2} \mathrm{E}_{2, t-1}+\cdots+\mathrm{a}_{n} \mathrm{E}_{n, t-1}+\mathrm{a}_{n+1} \mathrm{UM}_{t-1}+\epsilon_{n+1,}
\end{array}
$$

where $a_{i}$ denotes the coefficients on the stock returns, $E_{n}$ is the stock return for the n:th stock market, UM is either GPR, VIX or oil price change, and $\epsilon_{n}$ are the residuals. To create the spillover index we follow Diebold and Yilmaz (2014). The $h$-step error vector is created by starting with $x_{t+1, t}=\phi x_{t}$, then calculating the error vector $e_{t+1, t}$ using $e_{t+1, t}=x_{t+1}$ $x_{t+1 . t}=A_{0} u_{t+1}$. This has a covariance matrix $E\left(e_{t+1, t} e_{t+1, t}^{\prime}\right)=A_{0} A_{0}^{\prime}$. As a simple example, if we have a $2 \times 2$ matrix we get

$A_{0} A_{0}^{\prime}=\left(\begin{array}{ll}a_{0,11} & a_{0,12} \\ a_{0,21} & a_{0,22}\end{array}\right)\left(\begin{array}{ll}a_{0,11} & a_{0,21} \\ a_{0,12} & a_{0,22}\end{array}\right)=\left(\begin{array}{cc}a_{0,11}^{2}+a_{0,12}^{2} & a_{0,11} a_{0,21}+a_{0,12} a_{0,22} \\ a_{0,21} a_{0,11}+a_{0,22} a_{0,12} & a_{0,21}^{2}+a_{0,22}^{2}\end{array}\right)$ 
Now the cross-variance terms of the covariance matrix are interpreted as the spillover going from $1 \rightarrow 2$ or $2 \rightarrow 1$, and the feedback spillover as $1 \rightarrow 1$ or $2 \rightarrow 2$. To make an index of the spillover, the trace of the matrix $a_{0,11}^{2}+a_{0,12}^{2}+a_{0,21}^{2}+a_{0,22}^{2}$ is used, resulting in

$$
S=\frac{a_{0,12}^{2}+a_{0,21}^{2}}{a_{0,11}^{2}+a_{0,12}^{2}+a_{0,21}^{2}+a_{0,22}^{2}} \times 100
$$

or more generally,

$$
S=\frac{\sum_{h=0}^{H-1} \sum_{i, j=1}^{N} a_{h, i j}^{2}}{\sum_{h=0}^{H-1} \operatorname{Tr}\left(A_{h} A_{h}^{\prime}\right)}
$$

where $i, j$ are the spillovers from $i \rightarrow j$, when $i \neq j$, and $h$ is the length of the forecast step.

Most shocks to the reduced form representation are rarely orthogonal, which is in line with most economic reasoning. To estimate the reduced form variance decompositions, it is assumed that the generalized variance decomposition (GVD) framework of Pesaran and Shin (1998) exists. Then the GVD process can be stated as

$$
d_{i j}^{g H}=\frac{\sigma_{j j}^{-1} \sum_{h=0}^{H-1}\left(e_{i}^{t} \Theta_{h} \Sigma e_{j}\right)^{2}}{\sum_{h=0}^{H-1} e_{i}^{t} \Theta_{h} \sum \Theta_{h}^{\mathrm{t}} e_{j}},
$$

where $e_{i, j}$ is the selection vector for the $i, j$ :th element, $\Theta$ is the coefficient matrix, $\Sigma$ is the covariance matrix of the shock vector, and $\sigma_{j j}$ are the diagonal elements of $\Sigma$. Our computational spillover analysis ordering is based on the Klössner and Wagner (2014) approach.

From the reduced form model, the variance forecast decomposition is calculated using eq. (6), to get the connectedness estimate of the variables in the system. This representation of the spillover allows us to individually investigate the spillover from one entity $i$ to another entity $j$. Let $i$ represent a developed market, e.g., the U.S. and let $j$ be an emerging market, like China. The spillover from the U.S. to China is then represented by the expression $S_{i \rightarrow j}$, or vice versa $S_{j \rightarrow i}$ from China to the U.S. Summing up all the spillover effects that a given country receives, we get the total spillover from all markets. Let · be all markets and $i$ is the U.S., then the spillover $S_{\rightarrow i}$ is the total amount of spillover given to the U.S., and inversely, $S_{i \rightarrow \text {. is the total }}$ spillover that U.S gives to all the other markets. The net spillover (NS) is the difference in the pairwise spillover, $N S_{i}=S_{i \rightarrow j}-S_{j \rightarrow i}$, and in this example, it is the net spillover from the U.S. to China. The total net spillover $T N S_{i}=S_{i \rightarrow \cdot}-S_{\rightarrow}, i$, indicates how much net spillover e.g. the 
U.S. market has on all the other markets. The net spillover determines in what direction the spillover is likely to go and how important one country is in relation to the total spillover. When controlling for the robustness of the forecasting period, it is easier to control for the total net spillover $\left(\sum_{i=0}^{n} T N S_{i}\right)$. This way we can see how much the spillover changes when the forecast window $h$ is altered. The two input parameters that are pre-set in the model are the forecast window $h$ and the lag length of the VAR-model $p$. The $h$-parameter was set to 3 since it is likely that the investor forecasts of risk have a medium-term duration. The $p$-parameter was chosen based on the lowest AIC and SIC values, and this turned out to be 1 for all the models.

As discussed in section 3, the diversification aspect of investing in different stock markets is one of the main attractors for investors investment possibilities in different markets. Using the different stock indices and their response to each other and uncertainty will give us a clearer view on how the directionality from market to market works, especially during the times of rising geopolitical, stock market and oil price risks. Therefore, one key aspect is to look at the volatility spillover of the markets, and how it is affected during periods of increasing uncertainty. This gives the necessary information on how the market connectedness runs during volatile market conditions, and how investors should act in the global financial markets in these times. This will be even more illuminating using a rolling sample analysis.

\section{Empirical Results and Discussion}

Using the VAR-model with a one period lag and forecast window of three months, we created the spillover indices. Our main result for the return and volatility spillover analysis is that the GPR index has a weak or no impact at all on the stock markets. This indicates that the geopolitical uncertainty has low spillover predictability in the stock markets on average and that the stock market investments are not affected by geopolitical risks. However, for all the static estimations the emerging regional markets show high connectedness, which generally dominates over the spillover from the developed markets. This indicates that there are some opportunities for international diversification along the lines of Levy and Sarnat (1970) between emerging and developed markets, but not at the regional level. All markets show a net spillover to oil market which indicates that the oil prices receive the spillover from the stock markets, and hence, move in reaction to returns in the stock markets. Next, we discuss our results in more details. 


\subsection{Return spillover results}

The results in Table 5 show that the GPR index has low spillover effects into stock market returns in general. This means that GPR has a weak effect on the stock returns, on both the developed and emerging markets. GPR spillover ranges from $0.03 \%$ to $1.15 \%$. One possible explanation to this result could be that the GPR is constructed from newspaper articles collected mainly from American newspapers, which could introduce a self-selection bias in the news reported. It could also be that the GPR is not an overall good predictor for the economic policy outcomes so to better understand the results we will compare the GPR results to the Global Economic Policy Uncertainty (GEPU) in section 5.3.

There is, however, a strong possibility that the GPR is not affecting the stock markets, and that geopolitical uncertainty is not an important factor to determine the stock market movements. The main reason is that investors may not be able to correctly process the uncertainty from geopolitical events, e.g. they cannot adjust properly to new information because the outcome is uncertain, like in the case of Brexit referendum.

\section{$<<$ Insert Table 5 about here $>>$}

Results from the analysis of the spillover for the oil price in Table 5 show stronger relationships to the stock markets compared to the GPR index. China and Europe seem to obtain the highest impacts regarding the oil market spillover, which is quite logical in the sense that they both are dependent on the oil price for production purposes and do not have much own production. In general, oil price changes have a quite low spillover to the stock markets, only about $1-3 \%$. This is expected since the effect of the oil market to stock market is not as clear as the oil price effect on the real economy. One surprising result is that the net spillover from Russian stock market to the oil market is lower than to most other stock markets. The possible explanation is that Russia is relatively more affected by the oil price movements since it is one of the top producing oil countries in the world. The net spillover goes from the stock market to the oil market, indicating quite starkly as in Greenwood-Nimmo et al. (2015) that the oil market is largely affected by the stock markets. However, we also see that European (and the Czech Republic) stock markets have large spillovers to the oil market. This indicates strong interconnections between the financial market and the commodity markets, and hence, the real economy.

The results in Table 5 show that spillover from the VIX index is high to all markets, and some countries are more affected by the VIX, like Indonesia, Malaysia and Czech Republic, 
which have a net pairwise spillover of 1-3\% from the VIX to stock markets. Among the emerging countries, Chile and Russia show higher interaction with the VIX but they do not have the highest net spillovers among the emerging countries. This would indicate that they are more sensitive to the global financial risk than the other emerging countries. This is probably stemming from the equity flows from the developed markets into these regions, which would be in line with Balli et al. (2015). Because the VIX shows a much higher spillover to Europe and the U.S., there are smaller diversification benefits between these markets when you look at the financial risk.

In line with Diebold and Yilmaz (2009), we find that the return spillover among the developed markets is strong, meaning that all the developed markets seem to affect other developed markets. While they also have effects on the emerging markets, there seems to be clusters of countries in different regions that have stronger effects on each other compared to the effects of developed markets. Hence, the return spillovers exhibit a regional market effect especially in the South East Asia countries (Thailand, Malaysia and Indonesia) (see also, Duval et al. (2014), and Shin and Wang (2004)). Although similar patterns can be seen for the Japanese and Korean markets, Japan also shows strong connectedness to the European and global markets. Furthermore, the Czech Republic is strongly connected to the European market but not as much to the global market. This relationship is not as clear for the South American markets but the Peruvian market seems to be disproportionally affected by the Chilean market while the opposite relationship exists but is not to the same extent. Connection to the U.S. market is not that high either.

The regional market spillovers seem to be higher in general. This clearly points to contagion effects in the interregional markets, in line with Yarovaya et al. (2016), who found higher connectedness within a region. The cause for higher spillover in the regional market could be market synchronization, i.e., the business cycle co-movements that have increased the overall trade due to especially the intra-industry trade, as pointed out by Shin and Wang (2004). Balli et al. (2015) show that the proximity of countries and trade can affect the spillover, as pointed out in the description of the countries in section 2. Thailand, Malaysia and Indonesia have the highest trade percentage share between each other, and they are also the countries that show the highest regional spillover.

Let us focus on Thailand in more details. The main trading partners of Thailand are China and the U.S. (see Simoes and Hidalgo, 2011). Thailand exports most of its goods to China and the U.S. and imports most of its goods from China. The difference in the distance between Thailand and China, and the U.S. and Thailand are drastic, but the spillover is not that different. 
In addition, neither China, nor the U.S. has the highest spillover to Thailand. The results on stock market spillover show how Thailand is consistently more affected by Malaysia and Indonesia. This could be because these countries are not only connected through bilateral trade, but more importantly, through the Association of South East Asian Nations (ASEAN) trade agreement. While Peru and Chile seem to have quite large spillover to each other, they are also connected through the Pacific Alliance (PAFTA) which the U.S. is not involved with. Then there is also the European trade agreement (EEA) for Europe. These results suggest that the spillover between the stock markets could be strongly connected to the real economic activity, which is in line with Balli et al. (2015), Tsai (2017) and Shin and Wang (2004). The implication for investors is that the integration of the regional markets with high trade amongst themselves implies lower possibilities for diversification due to the increased contagion in the regional market. By the same token, diversification benefits among the developed markets are also limited since they have strong financial and trade integration. However, the developed markets show weaker spillover to the emerging markets, which implies diversification opportunities. Still, the net spillover from the developed markets is still quite high, implying that the emerging markets may receive negative return spillovers if the developed markets slow down.

\subsection{Results on volatility spillovers}

To capture the effects of the extreme market dependences (tails of the return distribution) we used a GARCH approach to capture the volatilities that could help us determine the simultaneous drops in stock indexes. Using this approach, we want to check for the variance risk that can occur especially during times off negative returns. The effect has been found by many researchers, like Kundu and Sarkar (2016) and Kim et al. (2015). This extreme dependence would negate the positive impact of diversification in different regions and stock markets. The specification of the GARCH process was based on different distribution models for various GARCH specifications. The reason behind this is that we want to find the best GARCH model to fit the data. The procedure for finding the optimal GARCH processes is described in the online Appendix S.A in the Supplementary Material of this article.

From the estimation results using the GPR variable reported in Table 6 we can see that there is higher spillover from GPR into Chile's and Turkey's stock markets about $0.82 \%$ and $1.30 \%$, respectively. That the Turkish market is clearly most connected to geopolitical risk index is perhaps understandable since a lot of the uncertainty stemming from the risk comes from the neighbouring Middle Eastern countries (Iraq, Iran and Syria). Thus, a conflict in this region could deter or make prospects more uncertain which makes their stock market more 
sensitive to increases in GPR. According to Fernandez (2007) the volatility shift in Turkish market during that time could depend on the geopolitical risk. However, that Chile has the second largest impact from the GPR spillover is unexpected but could be caused by neighbouring countries' (Bolivia and Argentina), whose instability influence the Chilean stock market.

The overall volatility spillover from GPR to most stock markets is low, and the only affected countries seem to be affected by the turmoil at the regional level. This indicates that investors have problems to predict the risk that makes GPR turn into actual problems for investments, or that the most instances have low impact on investment opportunities.

\section{$<$ Insert Table 6 about here $>>$}

The results in Table 6 show that the spillover going from and to the VIX risk is higher for the developed markets than for the emerging markets. Amongst the developed markets only the Japanese market shows weak interaction with the VIX, but it is generally receiving the spillovers with respect to volatility, and hence, could be largely affected by the increased uncertainty through the intra-market spillovers. The U.S. and European markets also have a positive volatility spillover on the VIX index risk, which is a quite intuitive result since the uncertainty about current prices in the stock markets will lead to uncertainty about future prices, too. From the emerging markets, China stands out as the one that has high positive spillover into the VIX index risk. Contrary to other studies, like Syriopoulos et al. (2015) and Li (2007, 2012), we find that China is receiving volatility spillovers from the U.S. and European markets. There are two possible explanations for this. One is that our measure of the Chinese stock market (MSCI China) is constructed from $85 \%$ of the stock market with A-, B-shares located in Shenzhen and Shanghai but also H-shares and red chip located in Hong-Kong. Inland China has low spillover while Hong-Kong has high spillover to the global market, (see also Li, 2012 and Diebold and Yilmaz, 2009), and hence, our measure could yield higher than expected spillovers since it does not strictly measure the inland China market. The other factor is the deregulation of the financial market, see $\mathrm{Li}$ (2012). It might have a higher impact on our results since we have a longer period of the deregulated Chinese stock markets under scrutiny.

Emerging markets connected to the developed markets, such as Chile and Peru to the U.S. market, and Czech Republic to the European markets, are more affected by the VIX risk than other emerging markets. Hence, there is a contagion effect from the developed markets to their neighbouring emerging markets. For the Czech Republic this is clearly linked to the EU 
membership, because the union has common policy agreements and institutions, and this increases the contagion risks because of the desegmentation of the markets, (see, Bekaert et al., 2013). For Chile and Peru, we find for the volatility spillover that the U.S. market shows high interaction with both countries, but this is not the case for the return spillover. However, we find in line with Yarovaya et al. (2016), Balli et al. (2015) and Kim et al. (2015) that emerging markets in the South East Asian region are generally not so much affected by the volatility spillover from the developed markets. The emerging markets in general show lower sensitivity to the VIX index risk, but they are generally receiving the spillover from other markets.

The oil price risk seems to be highly affected by negative volatility spillovers from all markets (see Table 6). This probably stems from the fact that plunges to the financial markets have real economic effects, with a drop in the demand for goods. Since the oil is the main input in many industries it is natural that it receives the spillover from the financial markets, and similar findings by Greenwood-Nimmo et al. (2015) support this view. One could argue that oil exporters benefit from positive volatility spillover (giving its spillover to other markets) on the stock markets, as Awartani and Magyereh (2013) have shown for the GULF countries (Bahrain, Iraq, Kuwait, Oman, Qatar and Saudi Arabia). However, we find that Russian stock market also shows negative volatility spillover into oil market returns. Because Russia is one of the largest producers of oil (according to Joint oil database initiative (JODI, 2017)) we may draw a conclusion that the positive spillover from the oil market to stock markets is confined to the GULF region in particular. Hence there is compelling evidence that oil is a bad diversification or poor hedging tool for the emerging stock markets, since the oil market is receiving the spillover. Furthermore, our findings show that the net spillover is going from the stock markets to the oil market and not the other way around. This is in stark contrast to the previous literature and theories (see e.g., Awartani and Magyereh, 2013), that argue that stocks are not driving the oil prices. There could be several explanations for this, but the increased financialization of commodities in general, as shown by Bekiros et al. (2017) and Reboredo and Uddin (2016) is probably the main reason for this result.

Our static analysis shows that volatility spillovers are more connected to the regional markets, and the same conclusion was drawn by Yarovaya et al. (2016) and Kundu and Sarkar (2016). This enforces our notion that the intra-regional markets are more strongly connected. Furthermore, the ASEAN countries in our sample show higher volatility spillovers amongst themselves than with the global markets. From the results reported in Table 6 and our stylized facts in Table 2, we are able to say that there might be a regional market business cycle that drives this behaviour. We can also see that Korean, Chinese and Japanese markets do not show 
as high a return spillover to the ASEAN countries, and as argued for the Chinese market this may be because of their stock market regulation. However, this argumentation does not hold for Korea and Japan. This could indicate that the trade connections of the countries belonging to the ASEAN agreement are the cause for the spillover among these markets. Similar argument could be made for the PAFTA countries for the return spillover. For volatility, both Peru and Chile show strong connectedness with both the U.S and European markets. This indicates that the South American countries are more integrated to the global market and that they show signs of contagion with the developed markets.

The Korean and Japanese markets also show high negative net volatility spillovers, and this makes them less attractive from a diversification perspective since they react heavily to the Indonesian, Thai and Malaysian markets. The U.S. market has negative net spillover on all the other markets, (see Table 6). The negative net spillover is higher to Chile, Peru and the developed European markets. However, the spillover to the East Asian countries is much lower in magnitude, which implies opportunities for diversification benefits, given the expected return. The return spillover tells a similar story although there is a marginal positive spillover to the European stock market as a whole, but not specifically to the Czech Republic market.

\subsection{Robustness tests}

In this paper the main focus is in the role of geopolitical risk measure, so next we will discuss the robustness of our results using the Global Economic Policy Uncertainty (GEPU) measure instead of GPR. These results are reported in Tables S7 and S8 in the online Supplementary Material of this paper. The main reason to compare GPR to GEPU is because they are constructed or partly constructed similarly using keyword searches from newspapers. However, the keywords may differ from each other, but the overall process is the same (See the online Supplementary Material Appendix S.B for the specifications of the searches). Figure S4 in the online Supplementary Material plots the difference between these two variables. However, based on the comparison in Figure S4 it is clear that they measure different aspects. GPR seems to only be sensitive to the geopolitical events, while GEPU responds more to the policy aspects. This can be seen in the periods from 1994 to 2001 and from 2007 to 2014 where they clearly show discrepancies in their patterns. Between 2007 and 2014 the GEPU picks up the global financial crisis and the European debt crisis, which GPR does not. This means that if GEPU has higher spillovers to the financial markets, the economic policy aspects are more important than the GPR aspects in pricing the financial assets. 
As we can see from Tables S7 and S8 in the Supplementary Material, GEPU has higher total spillovers than GPR, surmounting to $-40.77 \%$ and $-11.17 \%$, respectively, which is on par with the spillover effects for the oil market. In line with Tsai (2017), we find that the spillovers for China and the developed markets are higher. However, the developed markets are also the most affected by the GEPU. In the volatility analysis, the European markets have the largest impact on GEPU, which probably originates from the European debt crisis (in 2007-2014) and economic and policy uncertainty connected to the bank crises in Ireland and Iceland, and to the Southern European debt crisis, especially concerning Greece and the salvage packages, negotiated by the troika which left the market in uncertainty about future plans and development.

In conclusion, the GEPU has higher spillover effects than GPR and this strengthens the findings that pure geopolitical aspects have little or no effect on the markets on average. In addition, emerging markets, except China and the Czech Republic, are not as much affected by the GEPU as the other markets. Hence, there is little to be gained by looking at the pure geopolitical risk factor when investing in these stock markets. Instead, other uncertainty measures (GEPU, VIX and the commodity market risk) are more relevant for the movements in these markets.

\section{Rolling Sample Analysis}

To check for the stability of our results over time we changed the value of the forecast horizon parameter, $h$, from 1 month to the maximum of 9 months, to see how the total spillover values change. From Figures S5 and S6 in the Supplementary Material we see that the estimates are somewhat stable over time. The only deviant configuration is the forecasting window of one period $(h=1)$. Moreover, we can see that for $h>1$, the estimates converge to more or less the same values. We have therefore strong reasons to believe that the estimates are stable.

From Figures S5 and S6 we see a small but sharp decrease around 2001/02 in the connectedness of the markets for both returns and volatility spillovers, coinciding with the 9/11 attacks. Clearly, the spillover effects declined during this period because of the associated rise in geopolitical risk, so when we say that the GPR does not affect the market, we mean on average. From 2008 to 2013 we see increased connectedness based on the total spillover values. This would indicate that markets are getting more connected to each other which has decreased the diversification benefits. The hike in 2008 is strongly connected to the financial crisis and the following European debt crisis, and to better understand how this has affected the emerging 
market we re-estimated our models for this subsample (see Appendix S.C in the Supplementary Material for the results).

The VAR-modelling can also be sensitive to the chosen lag length $p$. From Figures S5 and S6 we can see that the changing lag length $p$ affects the spillover values more than changing the forecast horizon $h$. However, for the static analysis the lag length was 1 which was chosen based on the information criteria, and it also shows the lowest spillover in most time periods. From the static analysis for the period 2008-2013 we can see that the estimates reported in Tables S.C1 and S.C2 (Appendix S.C in the Supplementary Material) are generally pointing towards an increased connectedness of all markets, e.g., that the regional effect is less prevalent in this time period. For the return spillovers, controlling for the VIX index indicates that all the returns during this time period are affecting the VIX uncertainty, implying that the current prices are affecting the future uncertainty. This would indicate that during this time period, there should have been strong predictability in the markets.

Compared to the full sample results, the geopolitical uncertainty has a stronger impact on the market spillovers during this subsample. In general, we now observe low pairwise return spillovers, but for the volatility spillovers the geopolitical uncertainty increases in importance. It could mean that, after all, the GPR impacts on the financial markets, but its effect may be linked to globalization and financial integration.

\section{Conclusions and Policy Implications}

We have studied the stock market spillovers from the developed markets to the emerging markets while controlling for uncertainty, using both the return and volatility series for the spillover analysis. We did this by creating a spillover index from a VAR model with generalized error variance decomposition. The volatility series were estimated by determining the best possible GARCH process for each return series.

Our main finding is that the geopolitical risk (GPR) shows weak or no spillover to our chosen emerging stock markets. What is interesting with this result is that when we compare the result to the case of using another uncertainty measure, i.e., the Global Economic Policy Uncertainty (GEPU) index our analysis shows a higher spillover effect. This indicates that the important factor in the uncertainty measure is especially its connection to the economic activity and policy decisions.

Our second main finding is the higher spillover effect between regional markets in general, and within the Asian countries specifically, that was also observed in Yarovaya et al. 
(2016). We show that the most connected markets in the Asian region are Thailand, Malaysia and Indonesia. This may be caused by trade connections and especially the ASEAN free trade agreement. For the American market, there is the PAFTA and Europe there is the European Union (EU). The main link from free trade agreements to stock market is most likely the synchronization of the business cycles.

Our third finding is that the VIX market has higher impact on the Western developed stock markets, indicating the strong connectedness of these markets under financial uncertainty. The emerging markets are not to the same extent affected by the VIX market according to our return spillover results, but in volatility spillovers there is a heterogeneous effect depending on the emerging market. While South East Asian markets are generally unaffected, the South American and European markets are affected.

The oil price changes show negative net spillovers, which means that the oil market receives the spillover from all the other markets. Since the spillover is consistent over all markets, it would indicate that the oil market is sensitive to the overall market sentiment contrary to the results in e.g. Awartani and Magyereh (2013) and Greenwood-Nimmo et al. (2015). This indicates that the financialization of the commodity market has not helped diversification with respect to the stock market risks, (see also Bekiros et al. 2017 for same kind of results).

As answers to our research questions, first of all, we find that out of the uncertainty variables used in our study, VIX shows the strongest spillover effects to the emerging markets, whereas GPR had weak or no spillover effect to them. For the oil market, there was an opposite spillover effect, i.e., that the emerging stock markets showed spillover effects to the oil market. Second, regarding financial investment decisions, according to our results, VIX has strong spillover effects to financial markets, and especially to the developed markets, and hence, should be considered when making financial decisions. For the oil market, we found that all markets have positive net spillovers into it. The implication is that when the markets go down they will have spillover into oil market which will cause it to fall. GPR shows weak or no spillover effects, and hence, is not important for the diversification. Third, regarding the homogeneity of the emerging markets, the spillover effects in the emerging markets are connected to the regional markets and trade. Hence, the spillover is heterogeneous upon its location and trade. In connection to the question of diversification, the trade agreements are important to consider when trying to diversify a portfolio.

The main policy implication from our results is that the emerging markets seem to get affected more by real economic events than geopolitical uncertainty. What is important to 
consider is the link between the real economy and the financial markets and what affects that link. Among these factors are the trade agreements and the contents of them at the onset, in order to not create additional or unnecessary systemic risks in the financial markets.

From an investor's perspective, one can diversify a portfolio by investing some of the assets in the developed markets and some in the emerging markets from a financial market view. What an investor needs to have in mind is the real economic factors that drive the performance of regional markets. One way to take this into account is to consider different trade agreements and determine what is the likelihood of a new one to be established or old ones to change or end. In this respect, an example of one of the most recent uncertainty events is the Brexit, and its effects on the UK, Europe and all the other stock markets in the future.

\section{Acknowledgments}

We appreciate helpful comments and suggestions from Bo Sjö, Ali Ahmed, Stelios Bekiros, two anonymous referees, and the Editor Ali Kutan. We also greatly benefited from the discussions with the seminar participants at the Economics Division, Linköping University, Sweden, ERFIN conference in Warsaw School of Economics 2017 and the INFINITI2018 conference in Poznan, Poland. Gazi Salah Uddin is thankful for the financial support provided by the Jan Wallander and Tom Hedelius Foundations and Simon Foundation for travel grant. Part of this work was completed when Juha Junttila was visiting the Trinity Business School at Trinity College Dublin, Ireland, and Junttila thanks Brian Lucey and the School for their great hospitality during the visit, and the Research Foundation of the OP Group for financial support. This research belongs to the Research Agenda of the JyIMaF research group at the University of Jyvaskyla, Finland. 


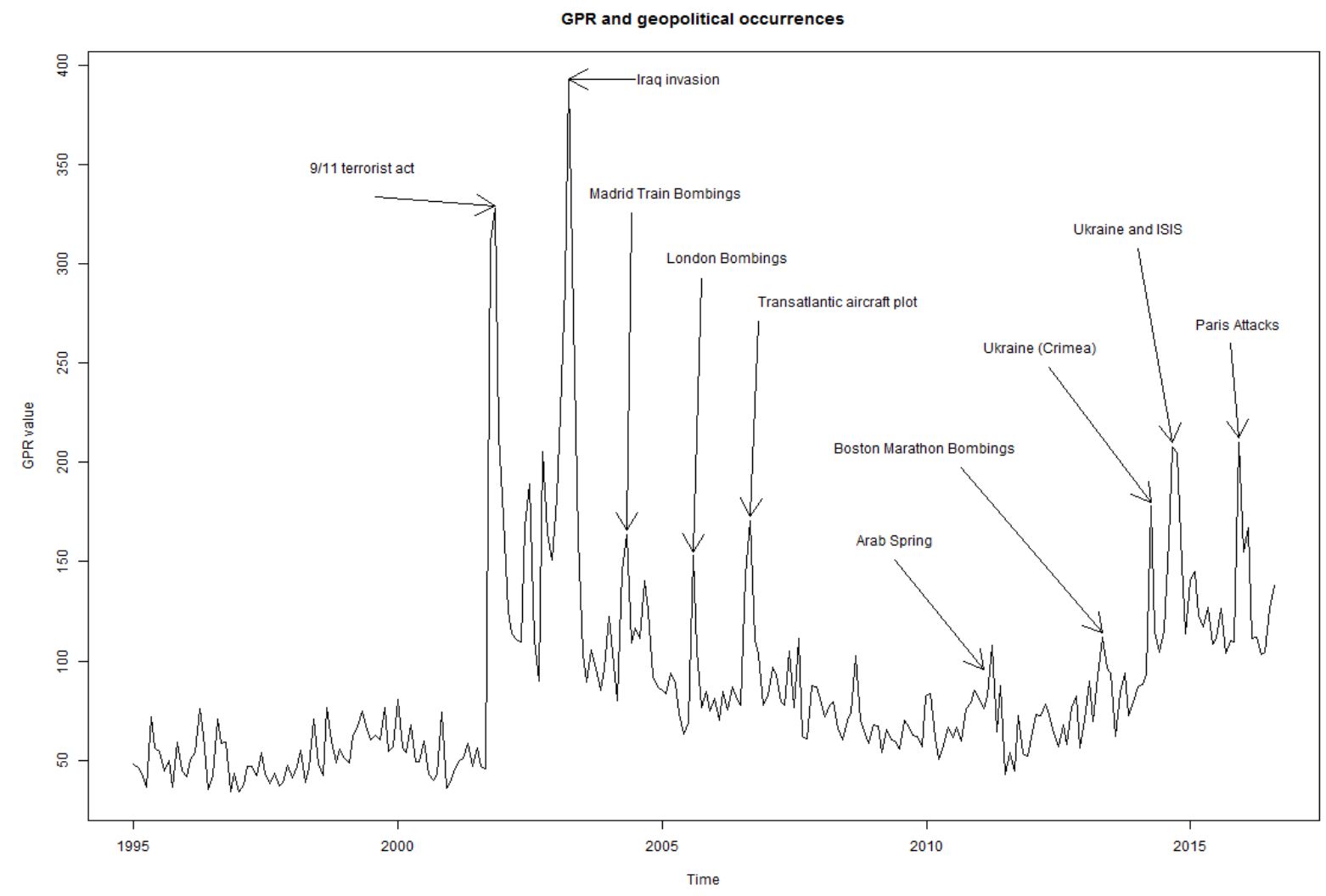

Fig. 1. Geopolitical events in connection to the GPR index. Note: Only the major peaks coincided with geopolitical events are pointed out. Source: Caldara and Iacoviello (2017). 


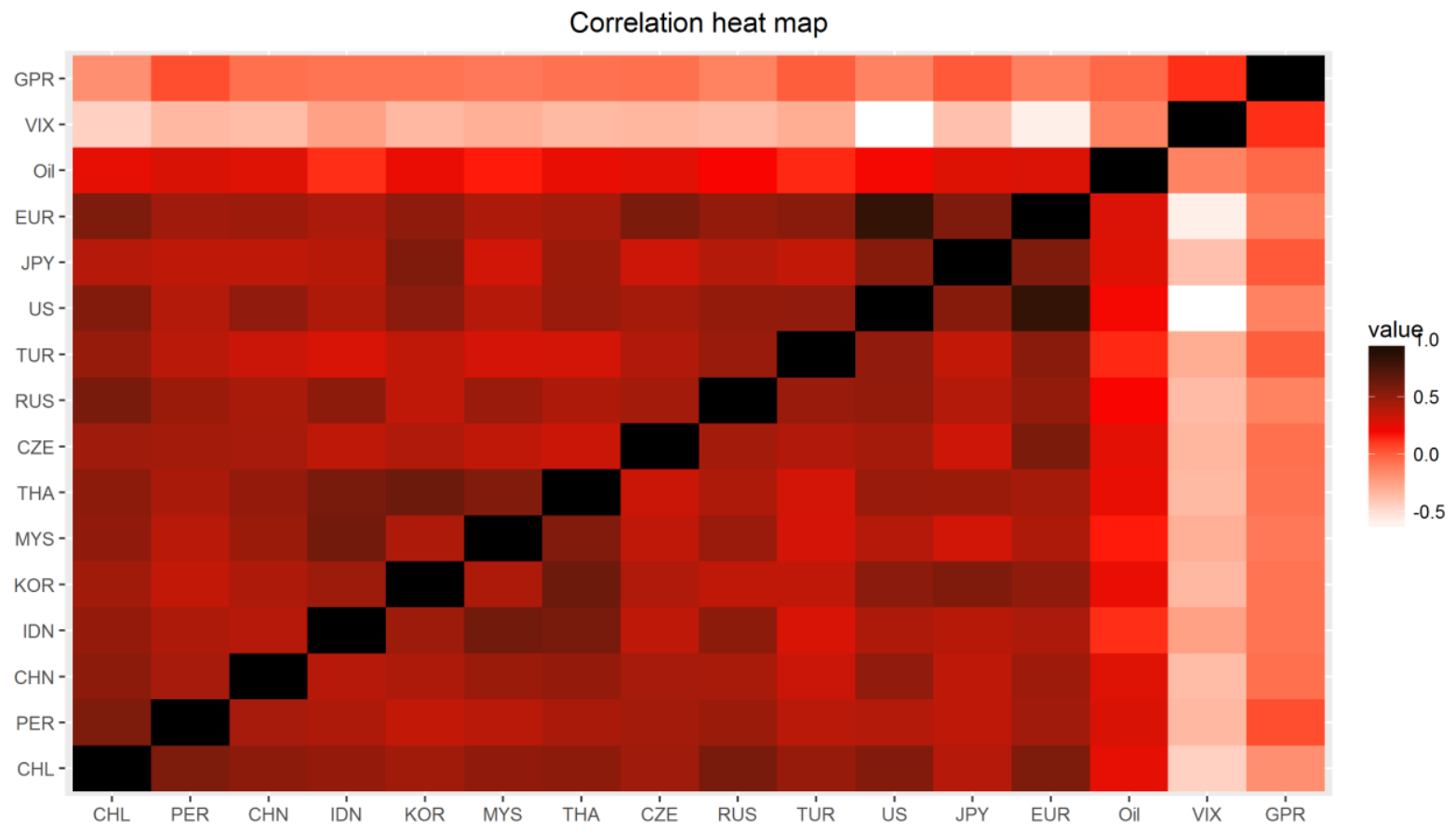

Fig. 2. Unconditional correlations between the variables (full sample). The country codes are CHL $=\mathrm{Chile}$, $\mathrm{PER}=$ Peru, $\mathrm{CHN}=$ China, $\mathrm{IDN}=$ Indonesia, $\mathrm{KOR}=$ Korea, $\mathrm{MYS}=$ Malaysia, THA $=$ Thailand, $\mathrm{CZE}=\mathrm{Czech}$ Republic, RUS = Russia, TUR = Turkey, US = USA, JPN = Japan, and EUR = Europe. The uncertainty measures are VIX = financial risk index, GPR = geopolitical risk index, Oil = oil price index change 
a) Return series for emerqing markets.
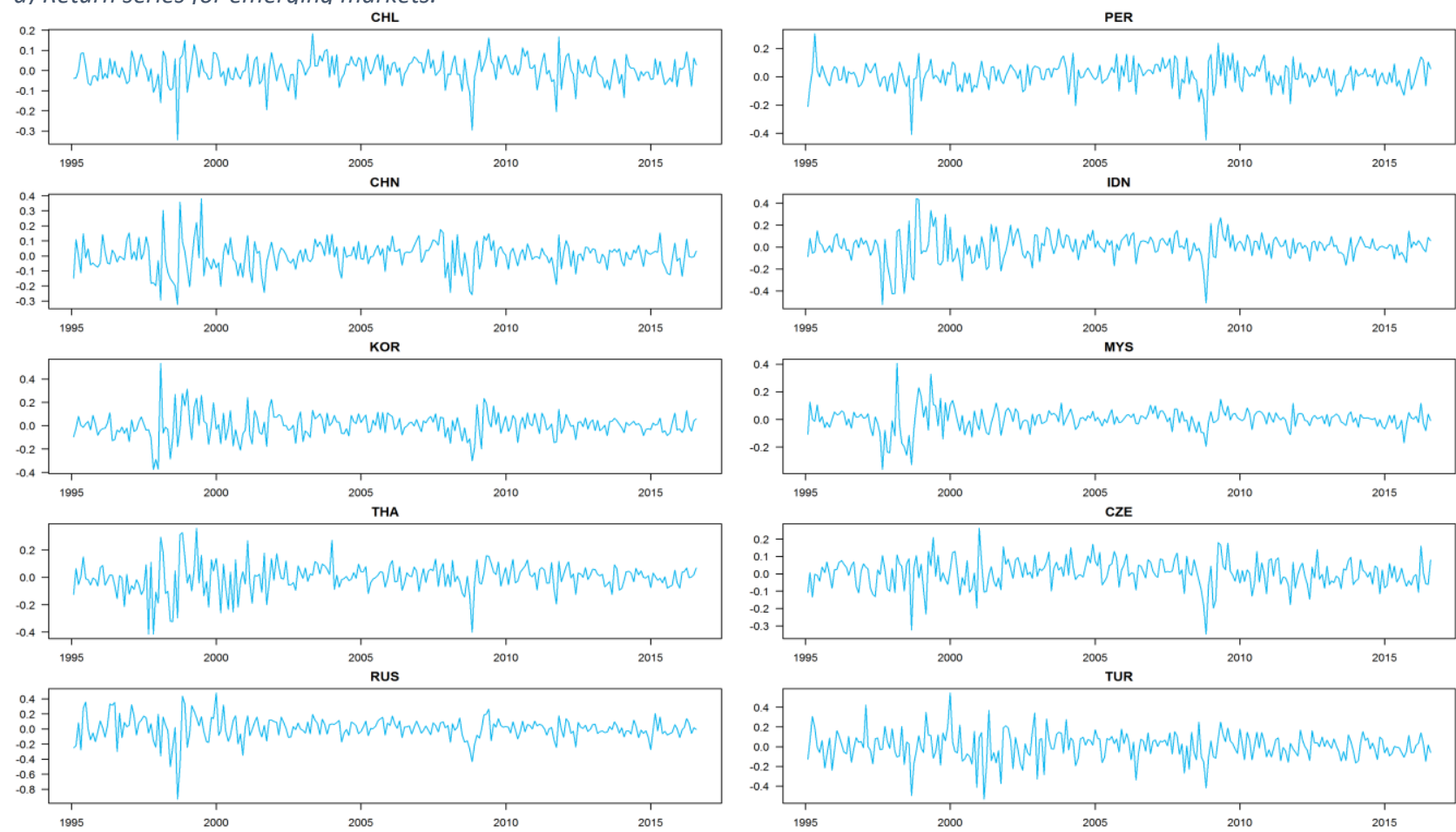

b) Return series for developed markets.

(1000

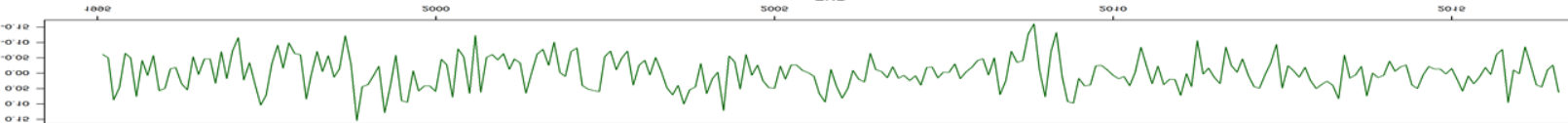

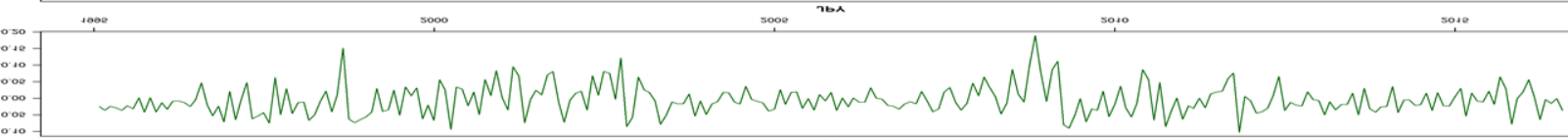

c) Uncertainty measures.
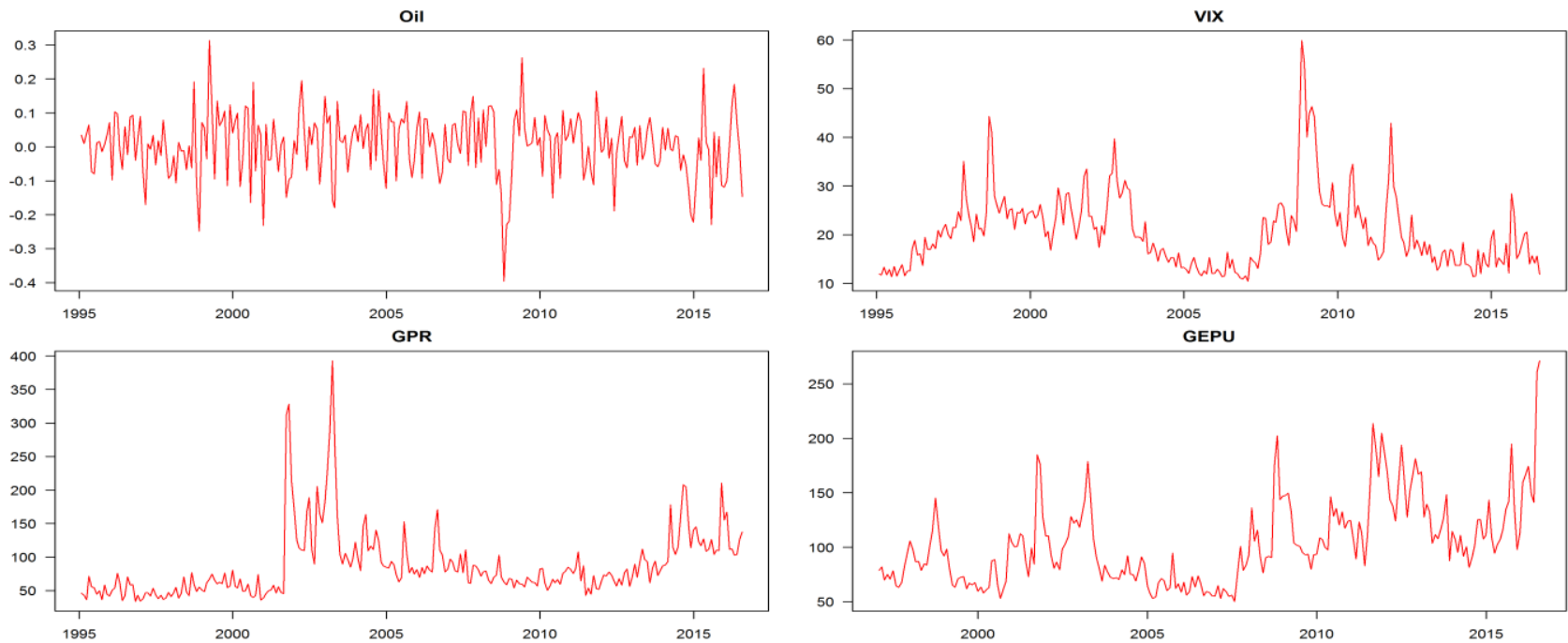

Fig. 3. Emerging and developed market returns and uncertainty measures. The country codes are $\mathrm{CHL}=\mathrm{Chile}$, PER $=$ Peru, $\mathrm{CHN}=$ China, IDN $=$ Indonesia, $\mathrm{KOR}=$ Korea, $\mathrm{MYS}=$ Malaysia, $\mathrm{THA}=$ Thailand, $\mathrm{CZE}=$ Czech Republic, TUR = Turkey, US = USA, JPN = Japan, and EUR = Europe. The uncertainty measures are VIX = financial risk index, GPR = geopolitical risk index, Oil = oil price index change, and GEPU $=$ Global Economic Policy Uncertainty Index 


\section{Table 1}

Financial openness progression in the emerging markets.

\begin{tabular}{ccccccccccccccccccc}
\hline \multicolumn{1}{c}{ Market capitalization (US\$; Billions) } & \multicolumn{4}{c}{ Listed companies (Total) } & \multicolumn{4}{c}{ Turnover ratio (\%) } \\
\hline Country & 1995 & 2000 & 2005 & 2010 & 2014 & 1995 & 2000 & 2005 & 2006 & 2014 & 1995 & 2000 & 2005 & 2006 & 2014 \\
\hline CHL & 72.93 & 60.40 & 136.49 & 341.80 & 233.25 & 282 & 260 & 245 & 227 & 230 & 15.20 & 9.54 & 14.98 & 16.95 & 11.632 \\
PER & & 9.75 & 24.14 & 103.35 & 78.84 & 242 & 209 & 193 & 199 & 211 & & 22.47 & 7.11 & 3.86 & 4.094 \\
CHN & & & 401.85 & 4027.84 & 6004.95 & 323 & 1086 & 1377 & 2063 & 2613 & & & 97.64 & 205.02 & 199.158 \\
IDN & 66.59 & 26.81 & 81.43 & 360.39 & 422.13 & 237 & 286 & 336 & 420 & 506 & 21.59 & 48.12 & 34.21 & 28.98 & 21.492 \\
KOR & 181.96 & 171.26 & 718.01 & 1091.91 & 1212.76 & 721 & 1242 & 1616 & 1781 & 1849 & 101.25 & 289.24 & 167.09 & 149.26 & 105.849 \\
MYS & 213.76 & 113.16 & 180.52 & 408.69 & 459.00 & 523 & 787 & 1015 & 948 & 895 & 28.13 & 46.41 & 24.73 & 28.08 & 31.078 \\
THA & 140.28 & 29.22 & 123.89 & 277.73 & 430.43 & 416 & 381 & 504 & 541 & 613 & 42.00 & 66.16 & 72.50 & 80.09 & 72.17 \\
CZE & 9.19 & 9.75 & 34.89 & & & 54 & 57 & 23 & 16 & 13 & 29.88 & 68.23 & 98.43 & & \\
RUS & & & & 951.30 & 385.93 & 340 & 21 & 414 & 556 & 254 & & & & 53.28 & 41.443 \\
TUR & 20.77 & 69.71 & 159.10 & 302.44 & 219.76 & 205 & 315 & 257 & 263 & 226 & 245.00 & 238.08 & 124.83 & 133.33 & 168.248 \\
\hline
\end{tabular}

Notes: The country codes for each country are as follow: CHL - Chile, PER - Peru, CHN - China, IDN - Indonesia, KOR - Korea, MYS Malaysia, THA - Thailand, CZE - Czech Republic, RUS - Russia, and TUR - Turkey. Market capitalization is the stock market value of the firms at the end of the year. Listed domestic companies gives the number of firms listed in the domestic market. Turnover ratio is the amount of stocks traded with respect to the total market capitalization. Source: The World Bank 


\section{Table 2}

Trade openness progression in the emerging markets.

\begin{tabular}{|c|c|c|c|c|c|c|c|c|c|c|c|c|c|c|c|}
\hline \multirow[b]{2}{*}{ Country } & \multicolumn{5}{|c|}{ Trade (\% of GDP) } & \multicolumn{5}{|c|}{ FDI, inflows (US\$; Billions) } & \multicolumn{5}{|c|}{$\begin{array}{l}\text { Portfolio equity inflows (US\$; } \\
\text { Billions) }\end{array}$} \\
\hline & 1995 & 2000 & 2005 & 2010 & 2014 & 1995 & 2000 & 2005 & 2006 & 2014 & 1995 & 2000 & 2005 & 2006 & 2014 \\
\hline CHL & 56.41 & 57.87 & 69.97 & 69.73 & 65.94 & -2.21 & -0.87 & -4.80 & -6.26 & -9.43 & -0.25 & -0.43 & 1.57 & 1.76 & 2.19 \\
\hline PER & 30.93 & 35.54 & 47.36 & 51.67 & 46.79 & -2.55 & -0.81 & -2.58 & -8.19 & -7.79 & 0.17 & 0.12 & 0.77 & 0.09 & -0.08 \\
\hline CHN & 34.76 & 39.75 & 62.89 & 48.89 & 45.65 & -33.85 & -37.48 & -90.38 & -185.75 & -144.97 & 0 & 6.91 & 20.57 & 31.36 & 51.92 \\
\hline$I D N$ & 53.96 & 71.44 & 63.99 & 46.70 & 48.06 & -3.74 & 4.55 & -5.27 & -11.10 & -14.73 & 1.49 & -1.02 & -0.17 & 2.13 & 3.26 \\
\hline KOR & 54.32 & 67.95 & 71.18 & 95.65 & 95.30 & 1.38 & -6.67 & -5.31 & 18.78 & 18.77 & 4.22 & 13.09 & 3.28 & 23.60 & 6.75 \\
\hline$M Y S$ & 192.11 & 220.41 & 203.85 & 157.95 & 138.31 & -4.18 & -1.76 & -0.99 & 4.46 & 5.44 & 0 & & -1.2 & & \\
\hline THA & 89.76 & 121.30 & 137.85 & 126.76 & 131.96 & -1.18 & -3.39 & -7.66 & -6.62 & 0.77 & 2.25 & 0.9 & 6.25 & 2.40 & -5.81 \\
\hline$C Z E$ & 84.23 & 98.51 & 122.28 & 129.26 & 158.73 & -2.53 & -4.94 & -11.63 & -4.92 & -4.01 & 1.24 & 0.62 & -1.54 & -0.23 & 0.27 \\
\hline$R U S$ & 55.18 & 68.09 & 56.71 & 50.36 & 48.45 & -1.46 & 0.50 & 2.37 & 9.45 & 35.05 & 0.05 & 0.15 & -0.16 & -4.89 & -12.97 \\
\hline TUR & 44.24 & 43.19 & 47.21 & 47.97 & 60.01 & -0.77 & -0.11 & -8.97 & -7.62 & -5.48 & 0.200 & 0.49 & 5.67 & 3.47 & 2.56 \\
\hline
\end{tabular}

Notes: For the country codes see Table 1 . Trade (\% of GDP) is the amount of goods trade divided by the national GDP. FDI is the foreign direct investment in companies or capital. Portfolio equity net inflows is the net inflow (inflow-outflow) to domestic equities, some entries are missing for MYS from the source. Source: World Bank. 


\section{Table 3}

Net exports between Developed and Emerging markets.

\begin{tabular}{l|ccccc} 
COUNTRIES & $\mathbf{1 9 9 5}$ & $\mathbf{2 0 0 0}$ & $\mathbf{2 0 0 5}$ & $\mathbf{2 0 1 0}$ & $\mathbf{2 0 1 5}$ \\
\hline USA-CHL & 1416.3 & -220 & -2248.7 & 3200.7 & 6707.277 \\
USA-PER & 682.8 & -436.8 & -3106.2 & 1392 & 3742.741 \\
USA-CHN & -36772.2 & -90251 & -218001 & -291105 & -365695 \\
USA-IDN & -4559.6 & -8618.6 & -9901.4 & -10449.6 & -12452.4 \\
USA-KOR & 522.5 & -13573.4 & -17852.7 & -11748.2 & -28328.7 \\
USA-MYS & -9162.7 & -15160.4 & -24224.9 & -12646.5 & -21535.7 \\
USA-THA & -5452.5 & -10623.6 & -13801.7 & -14642.5 & -17347.8 \\
USA-CZE & -76.6 & -271.3 & -1253.9 & -1130.5 & -2483.67 \\
USA-RUS & -1204.3 & -5529.2 & -12207.6 & -20566 & -9475.03 \\
USA-TUR & 801.5 & 536.3 & -1310.2 & 6124.7 & 1728.737 \\
JPN-CHL & -2293.87 & -2173.81 & -4045.62 & -5035.49 & -4336.29 \\
JPN-PER & -239.409 & 0.536854 & -421.194 & -1184.95 & -448.873 \\
JPN-CHN & -13988.6 & -24799.7 & -28434.4 & -3742.78 & -51382.6 \\
JPN-IDN & -4229.53 & -8767.26 & -11435.5 & -12336.7 & -8217.33 \\
JPN-KOR & 13961.56 & 10249.35 & 22279.91 & 33621.4 & 17218.53 \\
JPN-MYS & 6257.068 & -604.05 & -2061.79 & -5077.93 & -9525.43 \\
JPN-THA & 9589.491 & 3038.96 & 6988.361 & 13189.69 & 7563.31 \\
JPN-CZE & 25.18 & 95.57004 & 1044.577 & 1232.616 & 378.3912 \\
JPN-RUS & -3581.57 & -3984.53 & -1706 & -8112.17 & -10640 \\
JPN-TUR & 672.622 & 1039.655 & 1888.821 & 2159.288 & 1533.383 \\
EUR-CHL & -892.388 & -956.504 & -4451.21 & -4713.04 & 54.4528 \\
EUR-PER & -57.554 & -119.184 & -1407.17 & -3271.24 & -1407.04 \\
EUR-CHN & -11769.2 & -30332 & -94188.2 & -152925 & -131747 \\
EUR-IDN & 22.66229 & -4700.37 & -6213.38 & -8501.07 & -4603.08 \\
EUR-KOR & 1111.655 & -4822.45 & -12035.5 & -7206.17 & 11071 \\
EUR-MYS & -972.196 & -6216.38 & -6264.28 & -5949.36 & -5461.26 \\
EUR-THA & 1759.801 & -4357.27 & -3847.61 & -5495.69 & -3599.15 \\
EUR-CZE & 3032.616 & 1796.237 & 1847.966 & -10063.1 & -15083.6 \\
EUR-RUS & -10045.2 & -25561.1 & -47696.8 & -68854.2 & -47837.9 \\
EUR-TUR & 4480.703 & 9899.531 & 11972.09 & 22837.4 & 21222.67 \\
\hline & & & & & \\
\hline & & & & & \\
\hline
\end{tabular}

Note: The country codes for each country are as follow: CHL - Chile, PER - Peru, CHN - China, IDN - Indonesia, KOR Korea, MYS - Malaysia, THA - Thailand, CZE - Czech Republic, RUS - Russia, and TUR - Turkey, USA - the U.S, JPN Japan, EUR - EU. 


\section{Table 4}

Descriptive statistics for all the return and uncertainty variables (full sample)

\begin{tabular}{|c|c|c|c|c|c|c|c|c|}
\hline & Obs. & Mean & Std. Dev. & Skewness & Kurtosis & Jarque-Bera & ARCH-LM(5) & Sharpe \\
\hline CHL & 259 & 0.002 & 0.068 & -0.918 & 6.468 & $170.392 * * *$ & 4.497 & 0.029 \\
\hline PER & 259 & 0.008 & 0.088 & -0.839 & 6.967 & $205.254 * * *$ & 8.006 & 0.108 \\
\hline $\mathrm{CHN}$ & 259 & -0.001 & 0.097 & -0.032 & 4.920 & $41.414 * * *$ & $31.576 * * *$ & 0.019 \\
\hline IDN & 259 & 0.002 & 0.127 & -0.629 & 6.331 & $140.605^{* * *}$ & $57.889 * * *$ & 0.062 \\
\hline KOR & 259 & 0.003 & 0.106 & 0.218 & 6.373 & $128.529 * * *$ & $45.087 * * *$ & 0.060 \\
\hline MYS & 259 & 0.000 & 0.081 & -0.198 & 8.465 & $331.756^{* * *}$ & $62.012 * * *$ & 0.018 \\
\hline THA & 259 & -0.002 & 0.109 & -0.528 & 5.719 & $94.565 * * *$ & $39.142 * * *$ & 0.021 \\
\hline $\mathrm{CZE}$ & 259 & 0.004 & 0.083 & -0.516 & 4.776 & $47.082 * * *$ & $10.509 *$ & 0.064 \\
\hline RUS & 259 & 0.006 & 0.152 & -0.993 & 8.888 & $426.061 * * *$ & $36.692 * * *$ & 0.103 \\
\hline TUR & 259 & 0.005 & 0.143 & -0.250 & 4.841 & $40.805 * * *$ & 8.010 & 0.089 \\
\hline U.S. & 259 & 0.006 & 0.044 & -0.831 & 4.528 & $56.527 * * *$ & $23.472 * * *$ & 0.116 \\
\hline JPN & 259 & -0.001 & 0.052 & -0.078 & 2.954 & 0.270 & $15.932 * * *$ & -0.026 \\
\hline EUR & 259 & 0.003 & 0.052 & -0.837 & 4.986 & $74.877 * * *$ & $28.793 * * *$ & 0.053 \\
\hline Oil & 259 & 0.005 & 0.095 & -0.406 & 4.177 & $22.979 * * *$ & $12.117 * *$ & 0.081 \\
\hline VIX & 259 & 0.000 & 0.190 & 0.585 & 4.517 & $40.952 * * *$ & $11.398 * *$ & \\
\hline GPR & 259 & 0.004 & 0.282 & 1.317 & 10.796 & $745.778 * * *$ & 0.949 & \\
\hline
\end{tabular}

Notes: For the country codes and other notations see Table 1 and Figure 3. *,** and *** refer to the significance level of the test statistics at $10 \%, 5 \%$, and $1 \%$ levels, respectively. Jarque-Bera-test is a test for normality using the third and fourth moments (skewness and kurtosis). ARCH-LM(5) denotes the test for autoregressive features in the series. Sharpe ratio shows how well the return in question compares to a safe investment, and for consistency we used the U.S. T-bill return as the reference return. 


\section{Table 5}

Results from the static estimation of the pairwise, net and total return spillovers (in \%), when controlling for geopolitical uncertainty (GPR).

\begin{tabular}{|c|c|c|c|c|c|c|c|c|c|c|c|c|c|c|c|c|c|c|}
\hline & $\mathrm{CHL}$ & PER & $\mathrm{CHN}$ & IDN & KOR & MYS & THA & CZE & RUS & TUR & US & JPN & EUR & $\mathrm{VIX}$ & OIL & GPR & $\begin{array}{l}\text { FROM } \\
\text { INCL. }\end{array}$ & $\begin{array}{l}\text { FROM } \\
\text { EXCL. }\end{array}$ \\
\hline $\mathrm{CHL}$ & 21.10 & 7.05 & 6.52 & 5.30 & 4.13 & 5.77 & 5.84 & 3.98 & 7.56 & 5.95 & 6.92 & 3.65 & 7.41 & 6.08 & 1.58 & 1.15 & 100.00 & 78.90 \\
\hline PER & 9.59 & 27.73 & 6.26 & 4.86 & 2.96 & 4.66 & 5.33 & 5.56 & 6.13 & 4.37 & 4.82 & 3.32 & 6.18 & 5.91 & 2.29 & 0.03 & 100.00 & 72.27 \\
\hline $\mathrm{CHN}$ & 6.97 & 5.17 & 25.36 & 4.19 & 5.27 & 5.79 & 7.20 & 4.72 & 5.23 & 3.31 & 7.70 & 4.29 & 6.33 & 5.60 & 2.73 & 0.15 & 100.00 & 74.64 \\
\hline IDN & 7.02 & 4.84 & 6.29 & 23.91 & 6.39 & 9.18 & 9.52 & 4.06 & 5.75 & 2.78 & 5.97 & 4.45 & 4.87 & 3.96 & 0.72 & 0.29 & 100.00 & 76.09 \\
\hline KOR & 5.03 & 2.84 & 6.07 & 4.93 & 25.13 & 5.29 & 10.07 & 4.73 & 2.90 & 3.34 & 7.78 & 8.15 & 6.99 & 4.74 & 1.50 & 0.52 & 100.00 & 74.87 \\
\hline MYS & 6.69 & 3.74 & 6.04 & 8.66 & 6.69 & 24.87 & 9.57 & 3.44 & 5.68 & 3.88 & 5.59 & 3.77 & 5.27 & 5.00 & 0.70 & 0.37 & 100.00 & 75.13 \\
\hline THA & 6.45 & 4.50 & 6.60 & 8.39 & 9.58 & 7.90 & 23.96 & 2.87 & 4.08 & 2.46 & 6.04 & 5.78 & 4.77 & 4.57 & 1.65 & 0.39 & 100.00 & 76.04 \\
\hline CZE & 5.49 & 5.84 & 6.59 & 3.38 & 4.82 & 3.98 & 3.07 & 28.73 & 5.40 & 5.03 & 5.72 & 2.78 & 10.39 & 5.49 & 2.80 & 0.50 & 100.00 & 71.27 \\
\hline RUS & 9.12 & 5.55 & 6.45 & 5.75 & 2.89 & 6.28 & 4.50 & 4.99 & 24.48 & 5.62 & 7.40 & 3.41 & 6.48 & 5.56 & 1.23 & 0.31 & 100.00 & 75.52 \\
\hline TUR & 8.41 & 4.67 & 4.19 & 3.03 & 3.76 & 4.32 & 3.08 & 5.31 & 7.23 & 30.18 & 8.10 & 3.66 & 8.92 & 4.10 & 0.69 & 0.34 & 100.00 & 69.82 \\
\hline U.S. & 6.17 & 3.33 & 6.08 & 4.21 & 5.67 & 4.27 & 4.90 & 3.89 & 5.29 & 4.89 & 19.44 & 5.88 & 13.86 & 10.90 & 0.73 & 0.51 & 100.00 & 80.56 \\
\hline JPN & 4.75 & 3.59 & 5.78 & 3.37 & 8.97 & 3.22 & 6.29 & 2.66 & 3.59 & 3.56 & 8.81 & 27.73 & 8.89 & 6.85 & 1.90 & 0.04 & 100.00 & 72.27 \\
\hline EUR & 6.53 & 4.34 & 5.19 & 3.47 & 5.02 & 4.12 & 3.69 & 6.82 & 4.75 & 5.44 & 13.53 & 6.03 & 19.42 & 9.55 & 1.53 & 0.57 & 100.00 & 80.58 \\
\hline VIX & 6.41 & 4.95 & 7.48 & 2.20 & 3.62 & 4.06 & 3.60 & 4.40 & 4.52 & 3.09 & 12.77 & 5.93 & 12.02 & 23.64 & 1.12 & 0.21 & 100.00 & 76.36 \\
\hline OIL & 4.10 & 4.10 & 6.12 & 0.94 & 3.61 & 2.51 & 3.66 & 3.98 & 2.75 & 2.34 & 2.63 & 3.31 & 5.15 & 2.69 & 51.16 & 0.94 & 100.00 & 48.84 \\
\hline GPR & 2.15 & 1.86 & 0.29 & 0.31 & 0.76 & 0.74 & 0.24 & 0.12 & 0.56 & 0.50 & 3.58 & 0.15 & 2.85 & 1.39 & 0.64 & 83.87 & 100.00 & 16.13 \\
\hline TO INCL. & 115.99 & 94.09 & 111.31 & 86.89 & 99.27 & 96.95 & 104.55 & 90.25 & 95.89 & 86.73 & 126.80 & 92.31 & 129.80 & 106.01 & 72.97 & 90.19 & \multicolumn{2}{|c|}{1600.001119 .28} \\
\hline TO EXCL. & 94.89 & 66.37 & 85.95 & 62.98 & 74.14 & 72.08 & 80.58 & 61.51 & 71.41 & 56.55 & 107.36 & 64.58 & 110.38 & 82.38 & 21.81 & 6.32 & 1119.28 & 69.95 \\
\hline \multicolumn{19}{|l|}{ NET } \\
\hline $\begin{array}{l}\text { SPILL- } \\
\text { OVER }\end{array}$ & 17.58 & -6.91 & 17.89 & -16.43 & 2.64 & -5.38 & 3.10 & -4.45 & 6.27 & -8.45 & 25.73 & 1.07 & 31.15 & 7.83 & -30.86 & -40.77 & 0.00 & 0.00 \\
\hline
\end{tabular}

Notes: The return spillover is calculated using a 3-month forecasting window and a VAR(1) model. FROM and TO INCL. is the total spillover from and to the stock market in question (even itself), while EXCL is the spillover from all but itself. Net spillover is the total difference between all FROM and TO values for the market in question. 


\section{Table 6}

Results from the static estimations of the pairwise, net and total volatility spillovers (in \%), when controlling for the geopolitical risk (GPR).

\begin{tabular}{|c|c|c|c|c|c|c|c|c|c|c|c|c|c|c|c|c|c|c|}
\hline & $\mathrm{CHL}$ & PER & $\mathrm{CHN}$ & IDN & KOR & MYS & THA & CZE & RUS & TUR & US & JPN & EUR & VIX & Oil & GPR & $\begin{array}{l}\text { FROM } \\
\text { INCL. }\end{array}$ & $\begin{array}{l}\text { FROM } \\
\text { EXCL. }\end{array}$ \\
\hline $\mathrm{CHL}$ & 22.35 & 12.45 & 3.68 & 2.37 & 1.97 & 1.97 & 3.18 & 7.26 & 10.58 & 3.35 & 10.43 & 2.85 & 8.76 & 5.19 & 2.79 & 0.82 & 100.00 & 77.65 \\
\hline PER & 14.25 & 25.61 & 3.66 & 2.03 & 0.88 & 1.26 & 2.37 & 8.40 & 9.46 & 2.31 & 9.77 & 3.50 & 8.20 & 4.89 & 3.11 & 0.31 & 100.00 & 74.39 \\
\hline $\mathrm{CHN}$ & 7.57 & 5.71 & 34.15 & 5.05 & 10.89 & 1.49 & 6.24 & 5.23 & 7.05 & 0.66 & 3.71 & 2.60 & 3.68 & 4.52 & 0.77 & 0.69 & 100.00 & 65.85 \\
\hline IDN & 3.47 & 2.81 & 4.87 & 34.25 & 8.81 & 6.36 & 17.54 & 1.58 & 4.38 & 0.53 & 3.13 & 4.65 & 3.02 & 2.87 & 1.45 & 0.27 & 100.00 & 65.75 \\
\hline KOR & 2.46 & 1.42 & 4.00 & 15.43 & 53.26 & 0.58 & 11.80 & 0.41 & 1.06 & 0.34 & 1.03 & 3.51 & 0.89 & 2.90 & 0.45 & 0.46 & 100.00 & 46.74 \\
\hline MYS & 3.04 & 1.76 & 3.14 & 11.58 & 15.02 & 38.13 & 13.83 & 1.47 & 1.91 & 0.51 & 3.15 & 1.75 & 2.24 & 1.50 & 0.18 & 0.78 & 100.00 & 61.87 \\
\hline THA & 4.73 & 2.95 & 7.39 & 16.02 & 8.09 & 8.65 & 30.25 & 1.95 & 5.45 & 0.52 & 2.61 & 4.37 & 2.38 & 3.42 & 0.55 & 0.68 & 100.00 & 69.75 \\
\hline CZE & 10.07 & 10.01 & 2.76 & 1.22 & 1.17 & 1.14 & 1.43 & 30.69 & 7.41 & 4.18 & 8.77 & 2.70 & 8.59 & 6.26 & 3.47 & 0.14 & 100.00 & 69.31 \\
\hline RUS & 14.32 & 11.06 & 3.78 & 3.67 & 2.91 & 1.26 & 3.42 & 7.25 & 30.48 & 5.77 & 6.73 & 2.74 & 2.80 & 3.03 & 0.41 & 0.38 & 100.00 & 69.52 \\
\hline TUR & 6.88 & 4.34 & 1.33 & 0.66 & 0.50 & 0.32 & 0.71 & 6.42 & 9.40 & 47.16 & 7.98 & 2.02 & 4.90 & 5.17 & 0.90 & 1.30 & 100.00 & 52.84 \\
\hline U.S. & 10.55 & 8.61 & 3.34 & 1.85 & 0.41 & 1.72 & 1.82 & 6.58 & 5.03 & 3.79 & 22.89 & 4.41 & 15.53 & 11.21 & 2.13 & 0.13 & 100.00 & 77.11 \\
\hline JPN & 6.01 & 3.72 & 3.53 & 3.72 & 2.74 & 0.68 & 5.08 & 3.69 & 4.14 & 2.08 & 7.50 & 40.29 & 7.32 & 5.25 & 3.81 & 0.46 & 100.00 & 59.71 \\
\hline EUR & 9.81 & 7.06 & 3.05 & 2.12 & 0.32 & 1.39 & 1.85 & 6.80 & 2.39 & 2.58 & 16.33 & 4.67 & 26.69 & 10.77 & 4.11 & 0.06 & 100.00 & 73.31 \\
\hline VIX & 6.29 & 5.94 & 4.99 & 0.89 & 1.30 & 1.04 & 2.01 & 4.94 & 2.51 & 2.77 & 13.70 & 4.97 & 14.08 & 32.78 & 1.36 & 0.44 & 100.00 & 67.22 \\
\hline Oil & 6.12 & 5.88 & 2.08 & 2.34 & 0.46 & 0.08 & 1.04 & 7.63 & 2.42 & 1.86 & 6.18 & 6.40 & 10.57 & 4.86 & 41.45 & 0.61 & 100.00 & 58.55 \\
\hline GPR & 2.20 & 0.20 & 0.02 & 0.77 & 0.35 & 0.14 & 0.19 & 0.62 & 0.44 & 1.56 & 0.34 & 0.48 & 0.23 & 2.26 & 0.36 & 89.85 & 100.00 & 10.15 \\
\hline TO INCL. & 130.11 & 109.53 & 85.77 & 103.96 & 109.05 & 66.22 & 102.74 & 100.95 & 104.10 & 79.97 & 124.25 & 91.91 & 119.88 & 106.88 & 67.31 & 97.38 & 1600.00 & 999.73 \\
\hline TO EXCL. & 107.76 & 83.92 & 51.61 & 69.71 & 55.80 & 28.09 & 72.50 & 70.26 & 73.62 & 32.81 & 101.36 & 51.63 & 93.19 & 74.10 & 25.85 & 7.53 & 999.73 & 62.48 \\
\hline \multicolumn{19}{|c|}{ NET } \\
\hline OVER & 30.11 & 9.53 & -14.23 & 3.96 & 9.05 & -33.78 & 2.74 & 0.95 & 4.10 & -20.03 & 24.25 & -8.09 & 19.88 & 6.88 & -32.69 & -2.62 & 0.00 & 0.00 \\
\hline
\end{tabular}

Notes: See Table 5. 


\section{References}

Alfaro, L., Chanda, A., Kalemli-Ozcan, S. and Sayek, S. 2004. FDI and economic growth: the role of local financial markets. Journal of International Economics 64(1), 89-112.

Allen, F. and Gale, D. 2000. Financial Contagion. The Journal of Political Economy 108(1), 133.

Awartani, B. and Maghyereh, A. I. 2013. Dynamic spillovers between oil and stock markets in the Gulf Cooperation Council Countries. Energy Economics 36, 28-42.

Babus, A. 2016. The formation of financial networks. The RAND Journal of Economics 47(2), 239-272

Baig, T. and Goldfajn, I. 1999. Financial Market Contagion in the Asian Crisis. IMF Staff Papers 46(2), 167-195.

Baker, S., Bloom, N., Davis, S. 2016. Measuring Economic Policy Uncertainty. The Quarterly Journal of Economics 131, 1593-1636.

Balli, F., Hajhoj, H. R., Basher, S. A. and Ghassan, H. B. 2015. An analysis of returns and volatility spillovers and their determinants in emerging Asian and Middle Eastern countries. International Review of Economics and Finance 39, 311-325

Bekaert, G., Harvey, C. R., Lundblad, C. T. and Siegel, S. 2013. The European Union, the Euro, and equity market integration. Journal of Financial Economics 109(3), 583-603.

Bekiros, S. and Uddin, G. S. 2017. Extreme Dependence under Uncertainty: an application to Stock, Currency and Oil Markets. International Review of Finance 17/1, 155-162.

Bekiros, S., Nguyen, D. K., Sandoval Junior, L. and Uddin, G. S. 2017. Information diffusion, cluster formation and entropy-based network dynamics in equity and commodity markets. European Journal of Operational Research 256(3), 945-961.

Berger, D., Pukthuanthong, K. and Jimmy Yang, J. 2011. International diversification with frontier markets. Journal of Financial Economics 101(1), 227-242.

Bloomberg, 2013a. The Top 20 Emerging Markets. Available at: https://www.bloomberg.com/news/photo-essays/2013-01-31/the-top-20-emergingmarkets [Accessed: 2017-01-18].

Bloomberg, 2013b. How We Crunched Numbers to Rank Emerging and Frontier Markets. Available at: https://www.bloomberg.com/news/articles/2013-01-29/how-we-crunchednumbers-to-rank-emerging-and-frontier-markets [Accessed: 2017-01-18].

Brenner, M. and Galai, D. 1989. New financial instruments for hedging changes in volatility. Financial Analysts Journal 45(4), 61-65.

Brenner, M. and Galai, D. 1993. Hedging Volatility in Foreign Currencies. The Journal of Derivatives 1(1), 53-59.

Caldara, D. and Iacoviello, 2017. Measuring Geopolitcal Risk. Available at: https://www2.bc.edu/matteo-iacoviello/gpr.htm [Accessed: 2017-01-29].

Canova, F. 2007. VAR models, Methods for Applied Macroeconomic Research, Chapter 4. Princeton University Press, 103-152.

Caramazza, F., Ricci, L. and Salgado, R. 2004. International financial contagion in currency crises. Journal of International Money and Finance 23(1), 51-70.

Carrière-Swallow, Y. and Céspedes, L. F. 2013. The impact of uncertainty shocks in emerging economies. Journal of International Economics 90(2), 316-325.

Chicago Board Options Exchange, 2017. CBOE Volatility Index: VIX, accessed: 2017-02-15.

Davis, S. 2016. An Index of Global Economic Policy Uncertainty. Available at: www.policyuncertainty.com [Accessed: 2017-03-25].

Demirer, M., Diebold, F. X., Liu, L. and Yilmaz, K. 2017. Estimating global bank network connectedness. Journal of Applied Econometrics, forthcoming, DOI: 10.1002/jae.2585. 
Diamonte, R. L., Liew, J. M. and Stevens, R. L. 1996. Political risk in emerging and developed markets. Financial Analysts Journal 52(3), 71.

Diebold, F. and Yilmaz, K. 2009. Measuring Financial Asset Return and Volatility Spillovers, with Application to Global Equity Markets. The Economic Journal 119/1, 158-171.

Diebold, F. X. and Yilmaz, K. 2013. Measuring the Dynamics of Global Business Cycle Connectedness. SSRN Electronic Journal (111)

Diebold, F. X. and Yilmaz, K. 2014. On the network topology of variance decompositions: Measuring the connectedness of financial firms. Journal of Econometrics 82(1), 119-134.

Ding, Z., Granger, C. W. and Engle, R. F. 1993. A long memory property of stock market returns and a new model. Journal of Empirical Finance 1(1), 83-106.

Duval, R., Cheng, K., Hwa Oh, K., Saraf, R. and Seneviratne, D. 2014. Trade Integration and Business Cycle Synchronization: A Reappraisal with Focus on Asia. IMF Working Paper 14(52), 1

Engle, R. F. and Bollerslev, T. 1986. Modelling the persistence of conditional variances. Econometric Reviews 5(1), 1-50.

Engle, R. F. and Lee, G. G. J. 1993. A Permanent and Transitory Component Model of Stock Return Volatility. Available at SSRN: https://ssrn.com/abstract=5848

Engle, R. F., Gallo, G. M. and Velucchi, M. 2012. A MEM-Based Analysis of Volatility Spillovers in East Asian Financial Markets. The Review of Economics and Statistics 94(1), 222-233.

Fernandez, V. 2007. Stock Market Turmoil: Worldwide Effects of Middle East Conflicts. Emerging Markets Finance and Trade 43(3), 58-102.

Forbes, K. and Rigobon, R. 2001. Measuring Contagion: Conceptual and Empirical Issues, Claessens, S. \& Forbes, K. J. (ed.), International Financial Contagion, Chapter 3, Springer US, 43-66.

Ghalanos, A. 2015. Rugarch: Univariate GARCH models. R package version 1.3-6.

Glosten, L. R., Jagannathan, R. and Runkle, D. E. 1993. Forecasting stock market volatility using Garch models. The Journal of Finance 48(5), 1779-1801.

Greenwood-Nimmo, M., Nguyen, V. H. and Shin, Y. 2015. Measuring the Connectedness of the Global Economy. Melbourne Institute Working Paper Series, Working Paper No.7 / 15(7), 1-36.

JODI, 2017. Joint Organisations Data Initiative, URL: www.jodidata.org, Accessed: 2017-0507

Kim, B.-H., Kim, H. and Lee, B.-S. 2015. Spillover effects of the U.S. financial crisis on financial markets in emerging Asian countries. International Review of Economics and Finance 39, 192-210.

Klößner, S., \& Wagner, S. (2014). Exploring all VAR orderings for calculating spillovers? Yes, we can! - A note on Diebold and Yilmaz (2009). Journal of Applied Econometrics, 29(1), 172-179.

Koop, G., Pesaran, M. and Potter, S. 1996. Impulse response analysis in nonlinear multivariate models. Journal of Econometrics 74(1), 119-147.

Kundu, S. and Sarkar, N. 2016. Return and volatility interdependences in up and down markets across developed and emerging countries. Research in International Business and Finance 36, 297-311.

Levy, H. and Sarnat, M. 1970. International Diversification of Investment Portfolios. American Economic Review 60(4), 668-675.

$\mathrm{Li}, \mathrm{H}$. 2007. International linkages of the Chinese stock exchanges: a multivariate GARCH analysis. Applied Financial Economics 17, 285-297.

$\mathrm{Li}, \mathrm{H}$. 2012. The impact of China's stock market reforms on its international stock market linkages. Quarterly Review of Economics and Finance 52(4), 358-368. 
Luca, G. D., Genton, M. G. and Loperfido, N. 2006. A multivariate skew-garch model. Terrell, D. \& Fomby, T. B. (ed.), Econometric Analysis of Financial and Economic Time Series, Chapter Econometric, Analysis of Financial and Economic Time Series, Emerald Group Publishing Limited, Vol. 20, 33-57.

Nelson, D. B. 1991. Conditional Heteroskedasticity in Asset Returns: A New Approach. Econometrica 59(2), 347-370.

Pesaran, H. H. and Shin, Y. 1988. Capital Taxation and Production Efficiency in an Open Economy. Economics Letters 58, 17-29.

Pukthuanthong, K. and Roll, R. 2009. Global market integration: An alternative measure and its application. Journal of Financial Economics 94(2), 214-232.

Reboredo, J. C. and Uddin, G. S. 2016. Do financial stress and policy uncertainty have an impact on the energy and metals markets? A quantile regression approach. International Review of Economics and Finance 43, 284-298.

Sadorsky, P. 1999. Oil price shocks and stock market activity. Energy Economics 21, 449-469.

Shin, K. and Wang, Y. 2003. Trade Integration and Business Cycle Synchronization in East Asia 1. Asian Economic Papers 2(3), 1-20.

Shin, K. and Wang, Y. 2004. Trade integration and business cycle co-movements: The case of Korea with other Asian countries. Japan and the World Economy 16(2), 213-230.

Simoes, A. and Hidalgo, C. 2011. The Economic Complexity Observatory: An Analytical Tool for Understanding the Dynamics of Economic Development. Workshops at the TwentyFifth AAAI Conference on Artificial Intelligence, Available at: atlas.media.mit.edu [Accessed: 2017-04-26]

Sims, C. A. 1980. Macroeconomics and Reality. Econometrica 48(1), 1-48.

Syriopoulos, T., Makram, B. and Boubaker, A. 2015. Stock market volatility spillovers and portfolio hedging: BRICS and the financial crisis. International Review of Financial Analysis 39, 7-18.

The World Bank. 2017. World development Indicators. [Accessed: 2017-02-25]

Tsai, I. C. 2017. The source of global stock market risk: A viewpoint of economic policy uncertainty. Economic Modelling, 60(Sept), 122-131.

Ülkü, N. and Weber, E. 2014. Identifying the interaction between foreign investor flows and emerging stock market returns. Review of Finance 18(4), 1541-1581.

Yarovaya, L., Brzeszczy'nski, J. and Lau, C. K. M. 2016. Intra- and inter-regional return and volatility spillovers across emerging and developed markets: Evidence from stock indices and stock index futures. International Review of Financial Analysis 43, 96-114. 